\title{
A systematic review and meta-analysis of in situ versus composite bilateral internal thoracic artery grafting
}

\author{
Bobby Yanagawa, MD, PhD, ${ }^{\text {a }}$ Subodh Verma, MD, PhD, ${ }^{\text {a }}$ Peter Jüni, MD, ${ }^{b}$ Derrick Y. Tam, MD, \\ Amine Mazine, MD, ${ }^{a}$ John D. Puskas, MD, ${ }^{c}$ and Jan O. Friedrich, MD, PhD, MSc ${ }^{d}$
}

\section{ABSTRACT}

Objectives: This meta-analysis examines whether there is any advantage of coronary artery bypass graft with bilateral internal thoracic artery (BITA) as an in situ versus composite graft.

Methods: We searched MEDLINE and EMBASE Databases from 1996 to 2016 for studies that compared coronary artery bypass graft with BITA as in situ versus composite graft. Data were extracted by 2 independent investigators and metaanalyzed with the use of random effects.

Results: Two randomized controlled trials (RCTs; $\mathrm{n}=705$ ), 2 matched $(\mathrm{n}=1688)$, and 4 unadjusted observational studies $(\mathrm{n}=3517)$ met inclusion criteria. Composite grafting trended towards greater distal anastomoses $(+0.22$, $95 \%$ confidence interval, -0.01 to +0.45 anastomoses/patient; $P=.06$ [4 unadjusted observational studies]) and greater distal anastomoses using an internal thoracic artery $(+0.80,95 \%$ confidence interval, $0.41-1.18$ anastomoses/patient; $P<.001$ [1 RCT]). There were no differences in perioperative or longer-term composite cardiovascular outcomes comparing in situ versus composite BITA or individual outcomes of mortality, repeat revascularization, myocardial infarction, and cardiovascular mortality. Pooled results differed by study type with pooled results from lower-risk-of-bias RCTs typically showing increases in events rates, and pooled results from higher-risk-of-bias unadjusted observational studies typically showing decreases in event rates of in situ versus composite BITA. Post hoc subgroup analysis suggested possible improvements in all-cause mortality and revascularization for in situ BITA in studies with short-term $(<5$ years) versus longer-term follow-up, regardless of study type.

Conclusions: Our meta-analysis found that use of BITA as a composite graft configuration facilitated greater internal thoracic artery revascularization but both grafting strategies offer similar clinical outcomes. Our study supports the use of in situ and composite BITA for select patients but high-quality, long-term prospective trials are needed. (J Thorac Cardiovasc Surg 2017;153:1108-16)

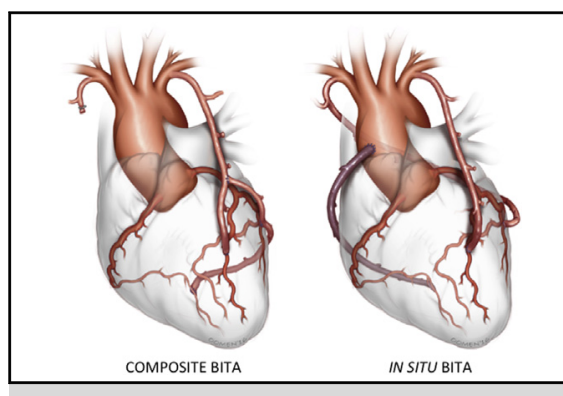

Surgical revascularization with composite versus in situ bilateral internal thoracic artery.

\section{Central Message}

In situ and composite bilateral internal thoracic artery configurations provide similar outcomes with respect to major adverse cardiovascular events.

\section{Perspective}

Strong data support the use of bilateral internal thoracic artery during coronary artery bypass grafting, but it is unclear whether one configuration is preferred over another. We found similar outcomes with respect to mortality, myocardial infarction, and repeat revascularization with either the in situ or composite bilateral internal thoracic artery configuration.

See Editorial Commentary page 1117.
Contemporary coronary artery bypass graft is still primarily performed by the use of a single internal thoracic artery and vein grafts. The sentinel work by Loop and colleagues ${ }^{1}$

\footnotetext{
From the ${ }^{a}$ Division of Cardiac Surgery, Department of Surgery, ${ }^{\mathrm{b}}$ Applied Health Research Centre, Li Ka Shing Knowledge Institute; ${ }^{c}$ Department of Cardiothoracic Surgery, Mount Sinai Beth Israel, New York, NY; and ${ }^{\mathrm{d}}$ Critical Care and Medicine Departments, St Michael's Hospital, University of Toronto, Toronto, Ontario, Canada.

Received for publication June 2, 2016; revisions received Oct 10, 2016; accepted for publication Nov 15, 2016; available ahead of print Dec 22, 2016.

Address for reprints: Bobby Yanagawa, MD, PhD, Division of Cardiac Surgery, Department of Surgery, University of Toronto, St. Michael's Hospital, 30 Bond St, 8th Floor, Bond Wing, Toronto, Ontario M5B 1W8, Canada (E-mail: yanagawab@smh.ca).

$0022-5223 / \$ 36.00$

Copyright (c) 2016 by The American Association for Thoracic Surgery

http://dx.doi.org/10.1016/j.jtcvs.2016.11.027
}

showed a survival advantage in favor of the left internal thoracic artery (LITA) to bypass the left anterior descending. In 1999, Lytle and colleagues ${ }^{2}$ then reported that 2 internal thoracic arteries (ITAs), or bilateral internal thoracic artery (BITA), was better than one. Numerous publications have since reported excellent long-term patency when using BITA, which has been supported by the American and European guidelines in select patients. ${ }^{3-9}$ The Arterial

Scanning this QR code will take you to supplemental figures and tables for this article. 

Abbreviations and Acronyms
BITA = bilateral internal thoracic artery
$\mathrm{CI}=$ confidence interval
ITA $=$ internal thoracic artery
LITA $=$ left internal thoracic artery
MACE $=$ major adverse cardiac event
$\mathrm{MD}=$ mean difference
MI = myocardial infarction
$\mathrm{RCT}=$ randomized controlled trial
RITA $=$ right internal thoracic artery

screening reviewer felt a citation potentially met inclusion criteria. Disagreements regarding inclusion were reconciled via consensus.

\section{Data Extraction and Quality Assessment}

Two reviewers independently abstracted data, including details of the publication, inclusion/exclusion criteria, patient demographics and cardiac risk factors, description of the interventions used, and outcome definitions and events. Risk of bias in randomized controlled trial (RCTs; including blinding of participants, method of sequence generation and allocation concealment, intention-to-treat analysis, early trial stopping for efficacy before the planned enrollment was completed, and loss to follow-up) and cohort studies (including retrospective vs prospective data collection, concurrent vs historical controls, and comparable baseline characteristics of cases and controls) were assessed with disagreements resolved by consensus.

\section{Data Analysis}

For observational studies that reported both unmatched and propensityscore matched data, we preferentially used the matched data. ${ }^{15,16}$ All analyses were performed with Review Manager (RevMan version 5.2; Cochrane Collaboration, Oxford, United Kingdom). For perioperative outcomes with similar follow-up between groups, log risk ratios were derived for binary outcomes and weighted mean differences (MDs) for continuous outcomes. For long-term outcomes with potentially different follow-up durations between groups, we derived the log incidence and corresponding standard error from numbers of reported events and accumulated person-years of follow-up. If these data are unavailable, we estimated log incidence rate ratios and corresponding standard errors from survival curves and log-rank $P$ values as previously described. ${ }^{17-19}$ Log incidence rate ratios were pooled via the generic inverse variance method (Tables E1 and E2). The number of anastomoses were treated as count data and analyzed as rates.

Two sets of observational studies from 2 research groups appeared to have at least partially overlapping patient populations. ${ }^{15,20-22} \mathrm{We}$ attempted to contact the authors but were unable to determine the degree of overlap. For outcomes in which 2 partially overlapping studies both provided results (for some perioperative outcomes among unadjusted observational data), we included only the larger ${ }^{15,20}$ of both pairs of unadjusted observational studies to avoid potentially double counting patients and exaggerating treatment effects. As a sensitivity analysis, we repeated each analysis including both studies from each potentially partially overlapping pair of studies to avoid excluding the nonoverlapping patient data. The sensitivity analysis only significantly changed the pooled analyses in one case (see Results section).

Post hoc subgroup analyses comparing studies with short versus long duration of follow-up, using a threshold of 5 years of follow-up, were conducted for pooled analyses of long-term outcomes.

All analyses used random effects models that incorporate between-trial heterogeneity and give wider, more conservative confidence intervals (CIs) when heterogeneity is present. ${ }^{23}$ We assessed statistical heterogeneity among trials using $I^{2}$, defined as the percentage of total variability across studies attributable to heterogeneity rather than chance, and used published suggestions for low (25\%), moderate $(50 \%)$, and high $(75 \%)$ heterogeneity. ${ }^{24}$ Individual trial and pooled summary results are reported with $95 \%$ CIs. Differences between pooled results of RCTs versus matched observational studies and versus unadjusted observational studies, and studies with shorter versus longer follow-up durations were evaluated using $\mathrm{z}$ tests. We did not publish a review protocol. PRISMA checklist is provided (Tables $\mathrm{E} 3$ and E4).

\section{RESULTS}

The initial search strategy yielded 1155 citations from MEDLINE and EMBASE, of which 14 were retrieved for 
TABLE 1. Study demographics

\begin{tabular}{|c|c|c|c|c|c|c|c|c|c|c|}
\hline \multirow[b]{2}{*}{ Reference } & \multirow[b]{2}{*}{ Study type } & \multicolumn{2}{|c|}{ Patients } & \multicolumn{2}{|c|}{ Age, $y$} & \multicolumn{2}{|c|}{ Female } & \multicolumn{2}{|c|}{ Diabetes } & \multirow[b]{2}{*}{ Mean FU, y } \\
\hline & & Comp & In situ & Comp & In situ & Comp & In situ & Comp & In situ & \\
\hline \multicolumn{11}{|l|}{$\mathrm{RCT}$} \\
\hline Glineur et al, $2008^{25}$ & RCT & 152 & 147 & 62 & 62 & $14(9 \%)$ & $25(14 \%)$ & $31(20 \%)$ & $29(19 \%)$ & 3 \\
\hline Nasso et al, $2009^{27}$ & RCT & 202 & 204 & 69 & 68 & $114(56 \%)$ & $116(57 \%)$ & $76(38 \%)$ & $77(38 \%)$ & 2 \\
\hline \multicolumn{11}{|l|}{ Obs matched } \\
\hline Hwang et al, $2011^{15}$ & Obs & 110 & 110 & $63 \pm 9$ & $62 \pm 9$ & $25(23 \%)$ & $24(22 \%)$ & $41(37 \%)$ & $41(37 \%)$ & 8.7 \\
\hline Di Mauro et al, $2016^{16}$ & Obs & 734 & 734 & $62 \pm 9$ & $62 \pm 9$ & $96(13 \%)$ & $95(13 \%)$ & $178(25 \%)$ & $173(24 \%)$ & 16.7 \\
\hline \multicolumn{11}{|l|}{ Obs unadjusted } \\
\hline Lev-Ran et al, $2002^{20}$ & Obs & 649 & 351 & - & - & $171(26 \%)$ & $66(19 \%)$ & $211(33 \%)$ & $95(27 \%)$ & - \\
\hline Lev-Ran et al, $2004^{21}$ & Obs & 437 & 162 & 67 & 65 & $137(31 \%)$ & $49(30 \%)$ & $437(100 \%)$ & $162(100 \%)$ & 3.5 \\
\hline Calafiore et al, $2000^{28}$ & Obs & 440 & 1378 & 62 & 62 & $78(18 \%)$ & $192(14 \%)$ & $133(30 \%)$ & $296(22 \%)$ & $2.8 \pm 2.1$ \\
\hline Kang, $2005^{22}$ & Obs & 51 & 49 & 63 & 60 & $8(16 \%)$ & $13(24 \%)$ & $22(41 \%)$ & $20(41 \%)$ & 0.4 \\
\hline
\end{tabular}

Comp, Composite; $F U$, follow-up; $R C T$, randomized controlled trial; Obs, observational.

full-text review (Figure E1). One randomized trial published perioperative and short-term outcomes followed by longer-term outcomes in a later publication. ${ }^{25,26}$

\section{Description of Included Studies and Patients}

There were 2 RCTs ( $\mathrm{n}=705$ patients; $2-7$ years followup), ${ }^{25,27} 2$ propensity score-matched observational studies $(\mathrm{n}=1688 ; 8.7-16.7$ years mean follow-up $),{ }^{15,16}$ and 4 unadjusted observational studies $(\mathrm{n}=3517$; $0.4-3.5$ years mean follow-up ${ }^{20-22,28}$ that met criteria for inclusion. The randomized trials were unblinded and did not specify whether allocation was concealed, but they used intention-to-treat analysis, were not stopped early for benefit, and had no or low percentage of randomized patients without outcome data (Table E5). One of the observational studies was prospective $\mathrm{e}^{22}$ and the remaining studies were retrospective; all included a comparison with concurrent controls. In 4 studies, there were differences in baseline characteristics between groups, with the composite group having more comorbidities or more severe coronary disease (Table 1 and Table E6) than the in situ group in 3 of these. Overall, the preoperative variables were comparable in both groups for age, sex, and prevalence of diabetes (Table 1).

\section{Operative Details}

Comparing in situ with composite grafting, we found there was a trend to a lower number of distal anastomoses for the unadjusted observational studies (MD, 0.22; $95 \%$ CI, 0.01 greater to 0.45 fewer anastomoses/patient, $P=.06$ [4 studies, 5366 patients]; Table 2, Figure E2). Decreases in the RCT and matched observational subgroups were not statistically significant. There were fewer distal anastomoses performed with ITA in the RCTs (MD, 0.80; 95\% CI, $0.42-1.18$ fewer anastomoses, $P<.001)$ and the unadjusted observational studies (MD, $0.48 ; 95 \% \mathrm{CI}$, $0.33-0.63$ fewer anastomoses, $P<.001$ ) with in situ grafting (Figure E3). This was reflected in shorter crossclamp times (10 minutes, $95 \%$ CI, 5-14 minutes shorter, $P<.001$ ) in the unadjusted observational studies, which was not different (4 minutes shorter, $95 \%$ CI, 11 minutes shorter to 3 minutes longer; $P=.28$ ) in the RCTs (interaction $P=.16$ ) (Figure E4) for the in situ group, and shorter cardiopulmonary bypass times (11 minutes, $95 \% \mathrm{CI}, 5-18$ minutes shorter, $P<.001)$ in the unadjusted observational studies, and not different ( 3 minutes shorter, 95\% CI, 14 minutes shorter to 8 minutes longer, $P=.63$ ) in the RCTs (interaction $P=.21$ ) (Figure E5). There was no difference in the proportion of procedures performed off-pump (risk ratio $1.02,95 \% \mathrm{CI}, 0.73-1.44 ; P=.89)$. Most of these analyses exhibited moderate-to-high heterogeneity.

\section{Surgical Outcomes}

There were no differences in 30-day mortality (Figure E6), perioperative MI (Figure E7), or perioperative stroke (Figure E8). There was no evidence of heterogeneity in any of the meta-analyses $\left(I^{2}=0 \%\right)$, and there were no subgroup differences in pooled results by study type (ie, all interaction $P$ values comparing pooled results of RCTs to pooled results of either matched observational or unadjusted observational studies were nonsignificant).

\section{Long-Term Outcomes}

For the longer-term outcomes including major adverse cardiac event (MACE; long-term mortality, nonfatal MI, and repeat revascularization; Figure 1), all-cause mortality (Figure 2), repeat revascularization (Figure 3), MI (Figure 4), cardiovascular mortality (Figure 5), and stroke (reported only by Glineur and colleagues ${ }^{25}$ [data not shown]), there were no differences comparing in situ versus composite BITA. Pooled results differed by study type, with pooled results from lower-risk-of-bias RCTs typically showing increases in events rates and pooled results from higher-risk-of-bias unadjusted observational studies typically showing decreases in event rates of in situ versus composite BITA (and pooled results from intermediaterisk-of-bias matched observational studies showing 
TABLE 2. Operative details

\begin{tabular}{|c|c|c|c|c|c|c|c|c|c|}
\hline \multirow[b]{2}{*}{ Reference } & \multicolumn{3}{|c|}{ Total distal anastomoses } & \multicolumn{3}{|c|}{ ITA anastomoses } & \multicolumn{3}{|c|}{ BITA sequential anastomoses $(\%)$} \\
\hline & Comp & In situ & $P$ & Comp & In situ & $\boldsymbol{P}$ & Comp & In situ & $\boldsymbol{P}$ \\
\hline \multicolumn{10}{|l|}{ Randomized controlled trial } \\
\hline Glineur et al, $2008^{25}$ & 3.8 & 3.5 & .48 & 0.6 & 1.1 & $<.01$ & - & - & - \\
\hline Nasso et al, $2009^{27}$ & - & - & - & - & - & - & $11 *(5 \%)$ & $4^{*}(2 \%)$ & - \\
\hline \multicolumn{10}{|l|}{ Observational matched } \\
\hline Hwang et al, $2011^{15}$ & $3.4 \pm 0.9$ & $3.0 \pm 0.7$ & $<.001$ & $2.8 \pm 0.7$ & $2.4 \pm 0.5$ & $<.001$ & $150 *(64 \%)$ & $58 *(35 \%)$ & $<.001$ \\
\hline Di Mauro et al, $2016^{16}$ & $3.2 \pm 0.9$ & $3.1 \pm 0.9$ & - & - & - & - & $305(42 \%)$ & $253(35 \%)$ & - \\
\hline \multicolumn{10}{|l|}{ Observational unadjusted } \\
\hline Lev-Ran et al, $2002^{20}$ & $3.2 \pm 0.6$ & $3.1 \pm 0.7$ & .8 & - & - & - & $402(62 \%)$ & $185(53 \%)$ & $<.001$ \\
\hline Lev-Ran et al, $2004^{21}$ & $3.2 \pm 0.8$ & $2.9 \pm 0.9$ & $<.001$ & - & - & - & $(57 \%)$ & $(35 \%)$ & $<.001$ \\
\hline Calafiore et al, $2000^{28}$ & $3.1 \pm 0.9$ & $2.9 \pm 0.8$ & .02 & $2.7 \pm 0.9$ & $2.2 \pm 0.6$ & $<.001$ & $225(51 \%)$ & $314(23 \%)$ & $<.001$ \\
\hline Kang, $2005^{22}$ & $3.3 \pm 0.9$ & $3.1 \pm 0.7$ & .1 & $2.7 \pm 0.7$ & $2.4 \pm 0.5$ & .005 & $31(57 \%)$ & $14(29 \%)$ & .003 \\
\hline
\end{tabular}

ITA, Internal thoracic artery; BITA, bilateral internal thoracic artery; $C P B$, cardiopulmonary bypass; OPCAB, off-pump coronary artery bypass graft; Comp, composite.

*Sequential anastomoses with ITA only.

intermediate results). No pooled increases $(10 \%-100 \%$ for RCT subgroups) or decreases (26\%-58\% for unadjusted observational study subgroups) in incidence rate ratios, however, achieved statistical significance despite their magnitude, likely as the result of small numbers. This differential effect by study type was particularly evident for MACE, all-cause mortality, and repeat revascularization where interaction $P$ values comparing the pooled results of the RCTs or the pooled results of the matched observational studies to the pooled results of the unadjusted observational studies were $.07, .09$, and .04 , respectively.

Post hoc subgroup analyses compared studies with shorter versus longer term follow-up, using a threshold of 5 years, where possible. For all-cause mortality (Figure E9, A), the RCT subgroup and the unadjusted observational study subgroup each included studies with less than and more than 5 years of follow-up, whereas for MACE (Figure $\mathrm{E} 9, B$ ) only the RCT subgroup and for revascularization (Figure E9, $C$ ) only the unadjusted observational study subgroup included both lengths of follow-up studies. Each of these comparisons showed a general directional pattern where the difference in adverse events favoring in situ versus composite BITA was more evident in the shorter term follow-up trials, although these differences only approached statistical significance for the unadjusted observational study subgroup comparison for the revascularization outcome (interaction $P=.08$ ), whereas for the other comparisons, interaction $P=.35-.40$. Interestingly, this directional pattern favoring in situ versus composite BITA also was observed comparing trials with shorter versus longer term follow-up within both the matched observational long-term follow-up subgroup, and the unadjusted observation long-term follow-up subgroup, although again these directional differences did not achieve statistical significance.

\section{DISCUSSION}

This meta-analysis is the first to compare outcomes of the 2 most common BITA grafting strategies. As suggested by this study, composite grafting was associated with a greater number of distal anastomoses using ITAs. Both strategies were similar with respect to the primary efficacy outcome, including a composite of all-cause death, nonfatal MI, and repeat revascularization or the individual components. This was the case despite the fact that there were more ITA distal anastomoses performed in the composite graft group with no differences in the incidence of ITA occlusion. A possible explanation is the greater comorbidities present in the composite cohort in 2 of the retrospective studies. ${ }^{20,28}$ Higher-risk-of-bias unadjusted observational studies typically showed greater benefit than the lower-risk-of-bias matched observational studies or RCTs for in situ versus composite grafts, which corresponded to the composite group having more comorbidities or more severe coronary disease than the in situ group in most of the unadjusted observational studies. In contrast, lower-risk-of-bias RCTs showed greater rates of adverse outcomes for in situ versus composite grafts, although none of the differences achieved statistical significance. Post hoc subgroup analysis suggests possible improvements in the in situ versus composite grafts in studies with less than 5 years of follow-up compared with studies with longer follow-up, but these results need to be interpreted cautiously as none of these differences, although consistent across study types and across outcomes, achieved statistical significance.

A potential drawback of the composite BITA technique is the reliance on a single inflow for multiple outflows and the risk of steal between the 2 arms of the composite graft as well as between sequential anastomoses. Several groups have shown a greater incidence of nonoptimal graft flows and graft failure with arterial composite and sequential grafting. ${ }^{29-32}$ Neragi-Miandoab and colleagues ${ }^{29}$ performed 
TABLE 2. Continued

\begin{tabular}{|c|c|c|c|c|c|}
\hline \multicolumn{3}{|c|}{ CPB/crossclamp times, min } & \multicolumn{3}{|c|}{ OPCAB (\%) } \\
\hline Comp & In situ & $\boldsymbol{P}$ & Comp & In situ & $\boldsymbol{P}$ \\
\hline $109 / 81$ & $100 / 73$ & $<.01 /<.01$ & 3.3 & 22.4 & $<.01$ \\
\hline- & - & - & 0 & 0 & 1.0 \\
\hline- & - & - & 100 & 100 & 1 \\
\hline- & - & - & 32 & 35 & - \\
\hline $80 \pm 39 / 68 \pm 30$ & $66 \pm 43 / 55 \pm 34$ & $<.001 /<.001$ & - & - & - \\
\hline $80 \pm 34 / 73 \pm 22$ & $78 \pm 29 / 68 \pm 21$ & $.5 / .2$ & 3.5 & 21.6 & $<.001$ \\
\hline- & - & - & 18.7 & 27.7 & \\
\hline- & - & - & 100 & 100 & 1 \\
\hline
\end{tabular}

a small, prospective randomized controlled trial of BITA as composite versus a free aortocoronary graft. Intraoperative transit-time flow demonstrated greater flow $(38.3 \pm 13.5 \mathrm{vs}$ $22.1 \pm 9.5, P<.01$ ) and conductance (flow/mean arterial pressure $)(0.45 \pm 0.16$ vs $0.28 \pm 0.11, P<.01)$ in freeRITAs anastomosed directly to the aorta than in composite
T-grafts. In a different multivariate analysis, use of a composite radial artery with ITA inflow correlated with competitive flow (odds ratio $1.90, P=.03$ ) and individual radial artery grafting inversely correlated with such (odds ratio $0.48, P=.04$ ) when proximal stenosis was between $50 \%$ and $75 \%{ }^{29}$

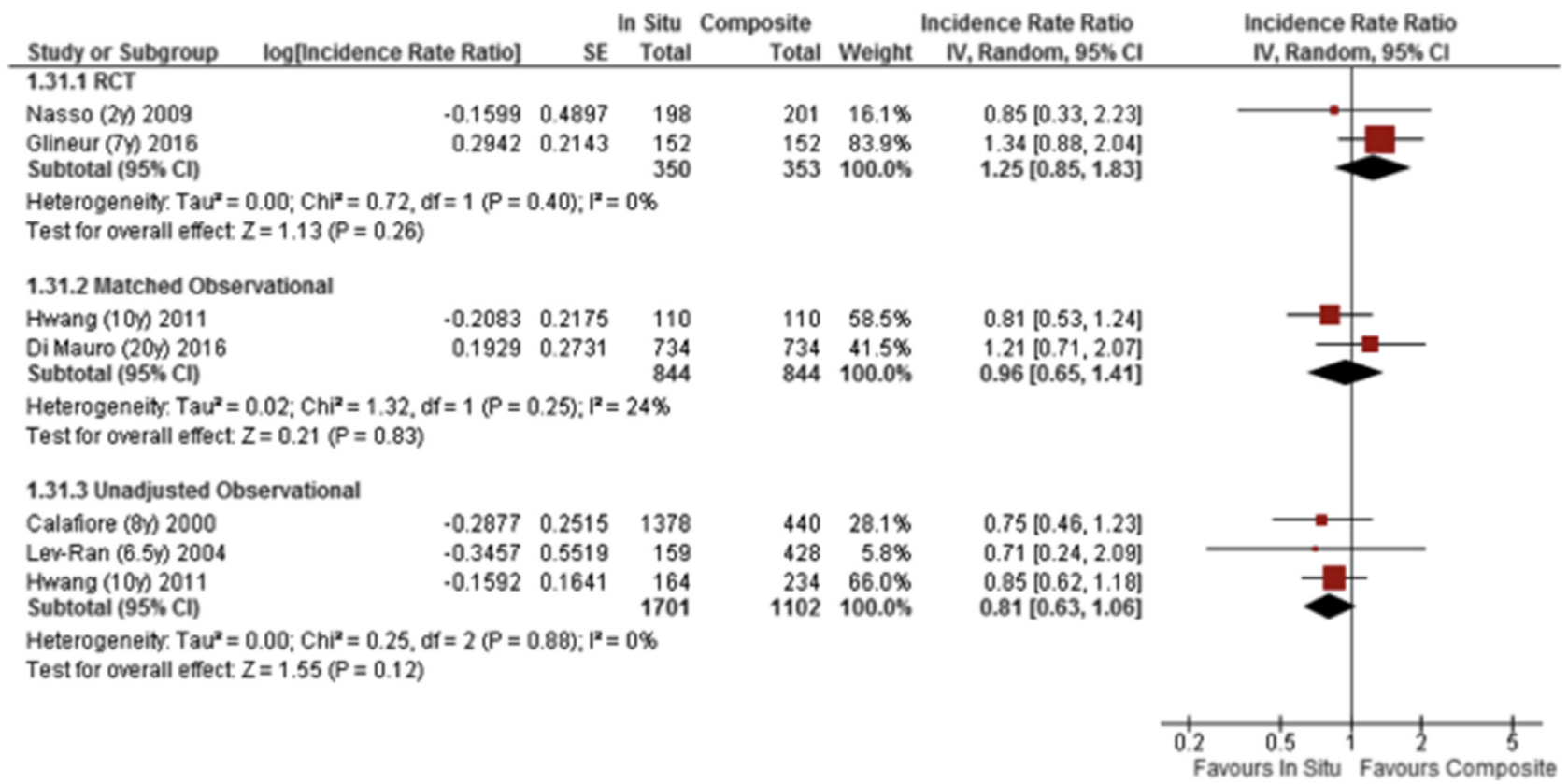

FIGURE 1. Forest plot for composite MACE, which includes death, nonfatal myocardial infarction, and revascularization for Calafiore and colleagues, ${ }^{28}$ Hwang and colleagues, ${ }^{15}$ Lev-Ran and colleagues, ${ }^{21}$ and Di Mauro and colleagues. ${ }^{16}$ Cerebrovascular events were also included for Glineur and colleagues ${ }^{15}$ (ie, MACCE). Angina and all coronary artery occlusions also were included for Nasso and colleagues. ${ }^{27}$ Individual study and pooled incidence rate ratios for composite cardiovascular outcome in RCTs versus matched observational studies versus unadjusted observational studies comparing patients with in situ versus composite BITA. The pooled incidence rate ratios with $95 \% \mathrm{CI}$ were calculated by the use of random-effects models. The time point that Kaplan-Meier survival curve outcome event estimates, or mean follow-up when absolute outcome events were reported in each study are shown in brackets after author name. Comparing the pooled result of the unadjusted observational studies to the pooled result of the RCTs (ie, the 2 subgroups with the most disparate pooled results) yields an interaction $P=.07$. Using MACE outcomes of 34/152 versus 28/152 instead of published MACCE outcomes for Glineur and colleagues $^{25}$ results in no significant changes to the pooled result for the RCTs $\left(1.13,95 \%\right.$ CI, $\left.0.72-1.75, P=.52, I^{2}=0 \%\right)$. Mean incidence rate for MACE ranged from $1.7 \%$ to $4.2 \%$ year among included studies. SE, Standard error; $C I$, confidence interval; $R C T$, randomized controlled trial. 


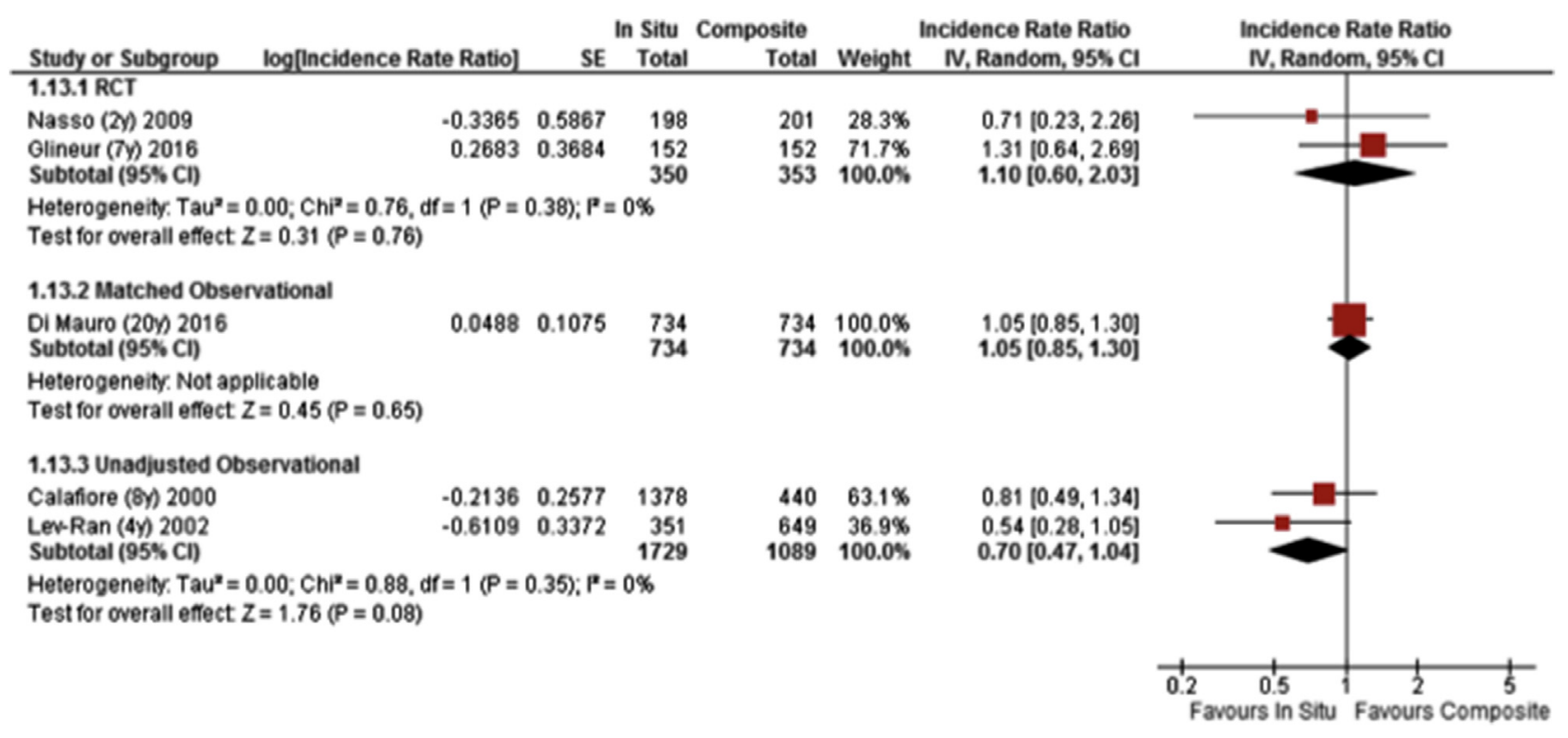

FIGURE 2. Forest plot for all-cause mortality. Individual study and pooled incidence rate ratios for all-cause mortality in RCTs versus matched observational studies versus unadjusted observational studies comparing patients with in situ versus composite BITA. The pooled incidence rate ratios with $95 \% \mathrm{CI}$ were calculated by the use of random-effects models. The time point that Kaplan-Meier survival curve outcome event estimates, or mean follow-up when absolute outcome events were reported in each study are shown in brackets after author name. Comparing the pooled result of the unadjusted observational studies to the pooled result of the RCTs yields an interaction $P=.22$, and to the pooled result of the matched observational studies, an interaction $P=.09$. Mean incidence rate for all-cause mortality ranged from $1.4 \%$ to $3.4 \% / y e a r$ among included studies. $S E$, Standard error; $C I$, confidence interval; $R C T$, randomized controlled trial.

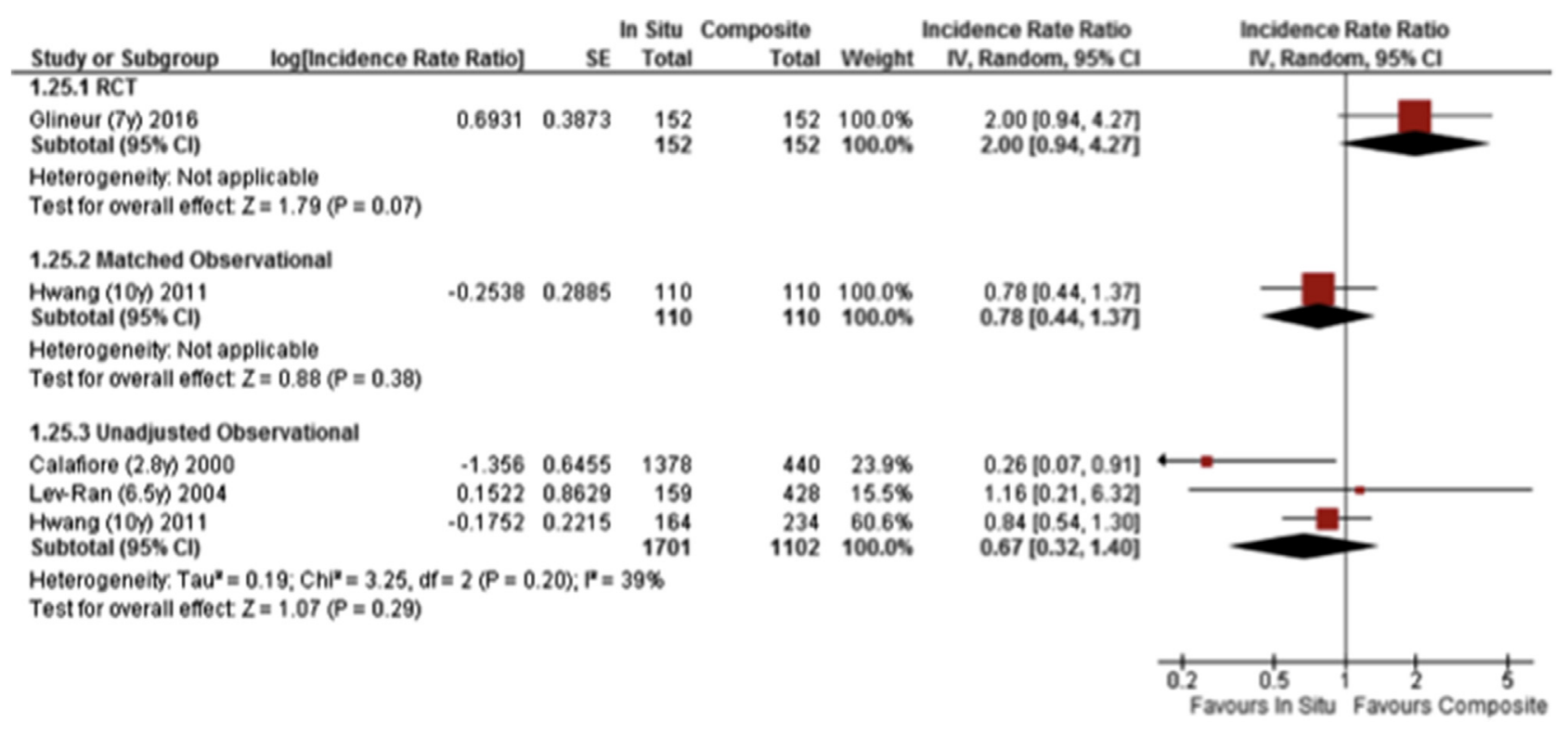

FIGURE 3. Forest plot for repeat revascularization. Individual study and pooled incidence rate ratios for repeat revascularization in RCTs versus matched observational studies versus unadjusted observational studies comparing patients with in situ versus composite BITA. The pooled incidence rate ratios with $95 \%$ CI were calculated by the use of random-effects models. The time point that Kaplan-Meier survival curve outcome event estimates, or mean follow-up when absolute outcome events were reported in each study are shown in brackets after author name. Comparing the pooled result of the unadjusted observational studies to the pooled result of the RCTs yields an interaction $P=.04$, and comparing the pooled result of the matched observational studies to the pooled result of the RCTs yields an interaction $P=.05$. Mean incidence rate for revascularization ranged from $0.2 \%$ to $1.6 \% /$ year among included studies. $S E$, Standard error; $C I$, confidence interval; $R C T$, randomized controlled trial. 


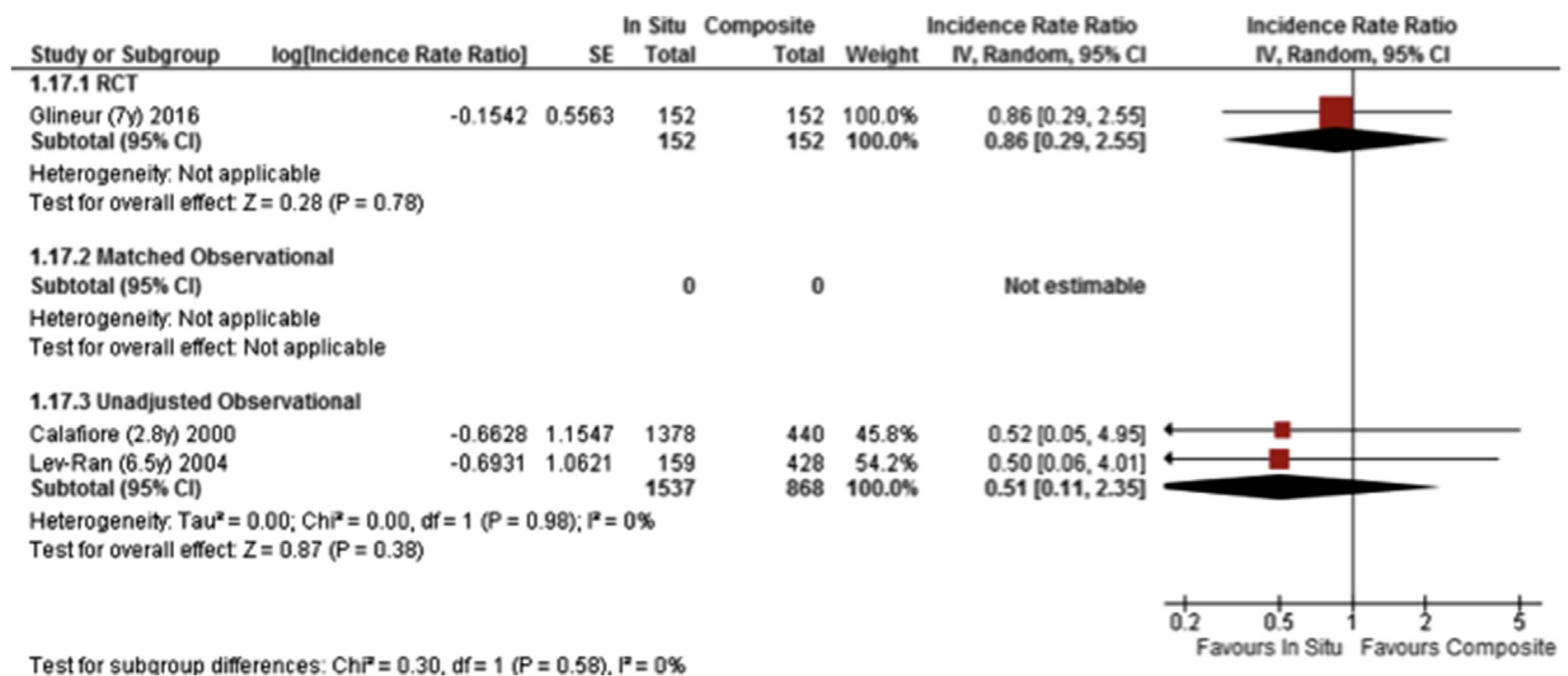

FIGURE 4. Forest plot for myocardial infarction. Individual study and pooled incidence rate ratios for myocardial infarction in RCTs versus matched observational studies versus unadjusted observational studies comparing patients with in situ versus composite BITA. The pooled incident rate ratios with $95 \%$ CI were calculated by the use of random-effects models. The time point that Kaplan-Meier survival curve outcome event estimates, or mean follow-up when absolute outcome events were reported in each study are shown in brackets after author name. The pooled result of the RCTs is similar to the pooled result of the unadjusted observational studies (interaction $P=.58$ ). Mean incidence rate for myocardial infarction ranged from $0.1 \%$ to $1.1 \% /$ year among included studies. SE, Standard error; $C I$, confidence interval; $R C T$, randomized controlled trial.

Nakajima and colleagues ${ }^{31}$ report greater antegrade flow for in situ LITA with RITA I-graft compared with LITARITA Y-grafts $(92.5 \%$ vs $89.7 \%, P=.049)$. In this study, the authors cleverly decide on the orientation of the I-graft (inferior wall to lateral wall or vice versa) to ensure that the most distal target has the greater anticipated flow. Thus, these authors suggest that the Y-graft may be more prone to competitive flow than a composite I graft constructed

\begin{tabular}{|c|c|c|c|c|c|c|c|}
\hline Study or Subgroup & log[Incidence Rate Ratio] & SE & $\begin{array}{l}\text { Situ } \\
\text { Total }\end{array}$ & $\begin{array}{r}\text { Composite } \\
\text { Total }\end{array}$ & Weight & $\begin{array}{l}\text { Incidence Rate Ratio } \\
\text { IV, Random, } 95 \% \mathrm{Cl}\end{array}$ & $\begin{array}{l}\text { Incidence Rate Ratio } \\
\text { IV, Random, } 95 \% \mathrm{Cl}\end{array}$ \\
\hline \multicolumn{8}{|l|}{ 1.22.1 RCT } \\
\hline Subtotal $(95 \% \mathrm{Cl})$ & & & $\mathbf{0}$ & $\mathbf{0}$ & & Not estimable & \\
\hline \multicolumn{8}{|c|}{$\begin{array}{l}\text { Heterogeneity. Not applicable } \\
\text { Test for overall effect: Not applicable }\end{array}$} \\
\hline \multicolumn{8}{|c|}{ 1.22.2 Matched Observational } \\
\hline Hwang (10y) 2011 & -0.1686 & 0.6037 & 110 & 110 & $12.4 \%$ & $0.84[0.26,2.76]$ & \\
\hline $\begin{array}{l}\text { Di Mauro }(20 y) 2016 \\
\text { Subtotal }(95 \% \mathrm{CI})\end{array}$ & -0.1603 & 0.227 & $\begin{array}{l}734 \\
844\end{array}$ & $\begin{array}{l}734 \\
844\end{array}$ & $\begin{array}{r}87.6 \% \\
100.0 \%\end{array}$ & $\begin{array}{l}0.85[0.55,1.33] \\
0.85[0.56,1.29]\end{array}$ & \\
\hline \multicolumn{8}{|c|}{$\begin{array}{l}\text { Heterogeneity. Tau }=0.00 ; \mathrm{Chi}^{2}=0.00, \mathrm{df}=1(P=0.99) ; \mathrm{I}^{2}=0 \% \\
\text { Test for overall effect: } Z=0.76(P=0.45)\end{array}$} \\
\hline \multicolumn{8}{|c|}{ 1.22.3 Unadjusted Observational } \\
\hline $\begin{array}{l}\text { Lev-Ran }(6.5 y) 2004 \\
\text { Subtotal }(95 \% \mathrm{CI})\end{array}$ & -0.8675 & 0.798 & $\begin{array}{l}159 \\
159\end{array}$ & $\begin{array}{l}428 \\
428\end{array}$ & $\begin{array}{l}100.0 \% \\
100.0 \%\end{array}$ & $\begin{array}{l}0.42[0.09,2.01] \\
0.42[0.09,2.01]\end{array}$ & \\
\hline \multicolumn{8}{|c|}{$\begin{array}{l}\text { Heterogeneity. Not applicable } \\
\text { Test for overall effect: } Z=1.09(P=0.28)\end{array}$} \\
\hline & & & & & & & 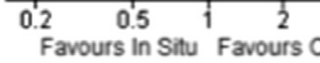 \\
\hline
\end{tabular}

FIGURE 5. Forest plot of cardiovascular mortality. Individual study and pooled incidence rate ratios for cardiovascular mortality in RCTs versus matched observational studies versus unadjusted observational studies comparing patients with in situ versus composite BITA. The pooled incidence rate ratios with $95 \%$ CIs were calculated by the use of random-effects models. The time point that Kaplan-Meier survival curve outcome event estimates, or mean follow-up when absolute outcome events were reported in each study are shown in brackets after author name. The pooled result of the matched observational studies is not statistically different to the pooled result of the unadjusted observational studies (interaction $P=.39$ ). Mean incidence rate for cardiovascular mortality ranged from $0.5 \%$ to $1.3 \%$ year among included studies. $S E$, Standard error; $C I$, confidence interval; $R C T$, randomized controlled trial. 
with ITA conduits, and that this competitive flow may beget graft failure. Sakaguchi and colleagues ${ }^{32}$ demonstrated less coronary flow reserve in composite grafts. Taken together, composite grafting requires greater consideration of the native coronary anatomy including degree of proximal stenosis and size of coronary perfusion bed. In some cases, composite grafting may lack driving pressure and may be at risk of competitive flow and graft failure; however, we did not show any differences in ITA patency and composite grafting does allow for greater ITA revascularization. Thus, overall we found no clear benefit of one grafting strategy over another.

We report no difference in incidence of stroke in the 2 cohorts. In our report, 2 studies were performed off-pump ${ }^{15,22}$ and 6 primarily on-pump. ${ }^{16,20,21,25-28}$ It is likely that a noaortic touch off-pump coronary artery bypass graft surgical revascularization will reduce the perioperative risk of stroke as suggested by previous studies and supported by a recent consensus statement but this could not be assessed here. ${ }^{33-35}$

\section{Study Strengths and Limitations}

This is the first systematic review and meta-analysis to compare in situ versus composite BITA grafting. The strength of this review is the use of rigorous methodology, including a reproducible and comprehensive literature search, clearly defined inclusion criteria, and duplicate citation review, data abstraction, and quality assessment of individual studies. Our systematic review highlights the small number of studies and small numbers of enrolled patients per study, with only a minority of these originating from randomized controlled trials.

Consequently, it is difficult to arrive at definitive conclusions from the limited data. In particular, data from observational studies should be interpreted with caution as even in the matched cohorts, there is likely a high degree of selection bias in allocating patients to either technique. It is likely that not all patients in each of the observational studies would even be eligible for both approaches, and within each study it is unclear how closely outcomes are related to operator rather than technique. The 2 publications by Lev-Ran and colleagues, ${ }^{20,21}$ as well as 2 other publications from another research group, ${ }^{15,22}$ may have some overlapping patients. As mentioned, for the few perioperative outcomes where data were available for potentially overlapping studies, all primary analyses included only the larger study by Lev-Ran and colleagues ${ }^{20}$ and the matched study from the other research group ${ }^{15}$ to avoid double counting some patients and potentially exaggerating treatment effects. However, this risks excluding nonoverlapping patients between the pairs of studies so in sensitivity analyses we repeated each analysis including both studies from each pair, which did not significantly change any of the analyses except for the total distal anastomoses pooled result which only became statistically significant when all studies were included. Finally, the composite grafts were composed of either $\mathrm{T}^{27,28}$ or Y-grafts ${ }^{15,16,20-22,25,26}$ in different studies. Given that both were associated with excellent outcomes, however, any hemodynamic difference is unlikely to be significant.

\section{CONCLUSIONS}

Composite grafting requires a balanced run-off in grafted territories but allows a greater number of distal anastomoses using ITA. We found similar outcomes with respect to mortality, MI, and repeat revascularization with in situ and composite BITA. Thus, our findings support the continued use and evaluation of BITA in both configurations. The lack of comparative data suggests the need for high-quality and long-term prospective trials focused on the optimal form of arterial revascularization.

\section{Conflict of Interest Statement}

Authors have nothing to disclose with regard to commercial support.

We are grateful to Dr David Glineur for kindly providing the number of patients with myocardial infarctions and the number with only strokes/cerebrovascular events (which allowed calculation of major adverse cardiac event rates rather than the published major adverse cardiac and cerebrovascular event rates) over the 7 years of follow-up for his $\mathrm{RCT}^{25}$ We also thank Dr George A. Tomlinson (Division of Biostatistics, Department of Medicine, University of Toronto) for statistical review.

\section{References}

1. Loop FD, Lytle BW, Cosgrove DM, Stewart RW, Goormastic M, Williams GW, et al. Influence of the internal-mammary-artery graft on 10-year survival and other cardiac events. N Engl J Med. 1986;314:1-6.

2. Lytle BW, Blackstone EH, Loop FD, Houghtaling PL, Arnold JH, Akhrass R, et al. Two internal thoracic artery grafts are better than one. J Thorac Cardiovasc Surg. 1999;117:855-72.

3. Endo M, Nishida H, Tomizawa Y, Kasanuki H. Benefit of bilateral over single internal mammary artery grafts for multiple coronary artery bypass grafting. Circulation. 2001;104:2164-70.

4. Stevens LM, Carrier M, Perrault LP, Hébert Y, Cartier R, Bouchard D, et al. Single versus bilateral internal thoracic artery grafts with concomitant saphenous vein grafts for multivessel coronary artery bypass grafting: effects on mortality and event-free survival. J Thorac Cardiovasc Surg. 2004;127:1408-15.

5. Hillis LD, Smith PK, Anderson JL, Bittl JA, Bridges CR, Byrne JG, et al. 2011 ACCF/AHA Guideline for Coronary Artery Bypass Graft Surgery. A report of the American College of Cardiology Foundation/American Heart Association Task Force on Practice Guidelines. Developed in collaboration with the American Association for Thoracic Surgery, Society of Cardiovascular Anesthesiologists, and Society of Thoracic Surgeons. J Am Coll Cardiol. 2011;58:e123-210.

6. Authors/Task Force members, Windecker S, Kolh P, Alfonso F, Collet JP, et al. 2014 ESC/EACTS Guidelines on myocardial revascularization: The Task Force on Myocardial Revascularization of the European Society of Cardiology (ESC) and the European Association for Cardio-Thoracic Surgery (EACTS) Developed with the special contribution of the European Association of Percutaneous Cardiovascular Interventions (EAPCI). Eur Heart J. 2014;35:2541-619.

7. Taggart DP, D'Amico R, Altman DG. Effect of arterial revascularisation on survival: a systematic review of studies comparing bilateral and single internal mammary arteries. Lancet. 2001;358:870-5. 
8. Grau JB, Ferrari G, Mak AW, Shaw RE, Brizzio ME, Mindich BP, et al. Propensity matched analysis of bilateral internal mammary artery versus single left internal mammary artery grafting at 17 -year follow-up: validation of a contemporary surgical experience. Eur J Cardiothorac Surg. 2012;41: $770-5$.

9. Puskas JD, Sadiq A, Vassiliades TA, Kilgo PD, Lattouf OM. Bilateral internal thoracic artery grafting is associated with significantly improved long-term survival, even among diabetic patients. Ann Thorac Surg. 2012;94:710-5.

10. Taggart DP, Altman DG, Gray AM, Lees B, Nugara F, Yu LM, et al. Randomized trial to compare bilateral vs. single internal mammary coronary artery bypass grafting: 1-year results of the Arterial Revascularisation Trial (ART). Eur Heart J. 2010;31:2470-81.

11. Buxton BF, Shi WY, Tatoulis J, Fuller JA, Rosalion A, Hayward PA. Total arterial revascularization with internal thoracic and radial artery grafts in triple-vessel coronary artery disease is associated with improved survival. J Thorac Cardiovasc Surg. 2014;148:1238-43.

12. Robinson BM, Paterson HS, Naidoo R, Dhurandhar V, Denniss AR. Bilateral internal thoracic artery composite y grafts: analysis of 464 angiograms in 296 patients. Ann Thorac Surg. 2016;101:974-80.

13. Hwang HY, Oh HC, Kim YH, Kim KB. Complete revascularization of the three vessel territories using a left internal thoracic artery composite graft. Ann Thorac Surg. 2015;100:59-66.

14. Paterson HS, Naidoo R, Byth K, Chen C, Denniss AR. Full myocardial revascularization with bilateral internal mammary artery $\mathrm{Y}$ grafts. Ann Cardiothorac Surg. 2013;2:444-52.

15. Hwang HY, Kim JS, Cho KR, Kim KB. Bilateral internal thoracic artery in situ versus y-composite graftings: five-year angiographic patency and long-term clinical outcomes. Ann Thorac Surg. 2011;92:579-85.

16. Di Mauro M, Iacò AL, Allam A, Awadi MO, Osman AA, et al. Bilateral internal mammary artery grafting: in situ versus Y-graft. Similar 20-year outcome. Eur J Cardiothorac Surg. 2016;50:729-34.

17. Parmar MK, Torri V, Stewart L. Extracting summary statistics to perform metaanalyses of the published literature for survival endpoints. Stat Med. 1998;17:2815-34.

18. Gillies CL, Abrams KR, Lambert PC, Cooper NJ, Sutton AJ, Hsu RT, et al. Pharmacologicaland lifestyle interventions to prevent or delay type 2 diabetes in people with impaired glucose tolerance: systematic review and meta-analysis. BMJ. 2007;334:299.

19. Meta-analysis of counts and rates. In: Higgins JPT, Green S, eds. Cochrane handbook for systematic reviews of interventions. Available at: http://handbook.cochrane.org/ chapter_9/9_4_8_meta_analysis_of_counts_and_rates.htm. Accessed October 5, 2016.

20. Lev-Ran O, Paz Y, Pevni D, Kramer A, Shapira I, Locker C, Mohr R. Bilateral internal thoracic artery grafting: midterm results of composite versus in situ crossover graft. Ann Thorac Surg. 2002;74:704-10.

21. Lev-Ran O, Mohr R, Pevni D, Nesher N, Weissman Y, Loberman D, et al. Bilateral internal thoracic artery grafting in diabetic patients: short-term and long-term results of a 515-patient series. J Thorac Cardiovasc Surg. 2004;127: $1145-50$.
22. Kang CH, Kim KB, Park CS, Paeng JC, Lee DS. Improvement of myocardial stress perfusion after off-pump revascularization using bilateral internal thoracic in situ grafts versus Y-composite grafts. Ann Thorac Surg. 2005;79:93-8.

23. DerSimonian R, Laird N. Meta-analysis in clinical trials. Control Clin Trials 1986; 7:177-88

24. Higgins JP, Thompson SG, Deeks JJ, Altman DG. Measuring inconsistency in meta-analysis. BMJ. 2003;327:557-60.

25. Glineur D, Hanet C, Poncelet A, D'hoore W, Funken JC, Rubay J, et al. Comparison of bilateral internal thoracic artery revascularization using in situ or Y graft configurations: a prospective randomized clinical, functional, and angiographic midterm evaluation. Circulation. 2008;118:S216-21.

26. Glineur D, Boodhwani M, Hanet C, de Kerchove L, Navarra E, Astarci P, et al. Bilateral Internal Thoracic Artery Configuration for Coronary Artery Bypass Surgery: A Prospective Randomized Trial. Circ Cardiovasc Interv. 2016;9: e003518.

27. Nasso G, Coppola R, Bonifazi R, Piancone F, Bozzetti G, Speziale G. Arterial revascularization in primary coronary artery bypass grafting: Direct comparison of 4 strategies--results of the Stand-in-Y Mammary Study. J Thorac Cardiovasc Surg. 2009;137:1093-100.

28. Calafiore AM, Contini M, Vitolla G, Di Mauro M, Mazzei V, Teodori G, et al. Bilateral internal thoracic artery grafting: long-term clinical and angiographic results of in situ versus Y grafts. J Thorac Cardiovasc Surg. 2000;120:990-6.

29. Neragi-Miandoab S, Michler RE, Lalezarzadeh F, Bello R, Derose JJ. What is the best proximal anastomosis for the free right internal thoracic artery during bilateral internal thoracic artery revascularization? A prospective, randomized study. Cardiol Res Pract. 2014;2014:972832.

30. Nakajima H, Kobayashi J, Toda K, Fujita T, Shimahara Y, Kasahara Y, et al A 10-year angiographic follow-up of competitive flow in sequential and composite arterial grafts. Eur J Cardiothorac Surg. 2011;40:399-404.

31. Nakajima H, Kobayashi J, Toda K, Fujita T, Shimahara Y, Kasahara Y, et al Angiographic evaluation of flow distribution in sequential and composite arterial grafts for three vessel disease. Eur J Cardiothorac Surg. 2012;41:763-9.

32. Sakaguchi G, Tadamura E, Ohnaka M, Tambara K, Nishimura K, Komeda M Composite arterial Y graft has less coronary flow reserve than independent grafts Ann Thorac Surg. 2002;74:493-6.

33. Moss E, Puskas JD, Thourani VH, Kilgo P, Chen EP, Leshnower BG, et al Avoiding aortic clamping during coronary artery bypass grafting reduces postoperative stroke. J Thorac Cardiovasc Surg. 2015;149:175-80.

34. Kim KB, Kang CH, Chang WI, Lim C, Kim JH, Ham BM, et al. Off-pump coronary artery bypass with complete avoidance of aortic manipulation. Ann Thorac Surg. 2002;74:S1377-82.

35. Puskas JD, Martin J, Cheng DC, Benussi S, Bonatti JO, Diegeler A, et al. ISMICS consensus conference and statements of randomized controlled trials of off-pump versus conventional coronary artery bypass surgery. Innovations (Phila). 2015; 10:219-29.

Key Words: bilateral internal thoracic artery, coronary artery bypass graft, graft patency

Readers who found these articles interesting may also like to read the following papers found in recent and future issues of our sister publications, Seminars in Thoracic and Cardiovascular Surgery and Operative Techniques in Thoracic and Cardiovascular Surgery!

\section{Acquired: Coronary Artery Disease}

Open Aortic Arch Reconstruction After Coronary Artery Bypass Surgery: Worth the Effort? Eduard Quintana. Semin Thoracic Surg 2016:26-35

Risky Business or Acceptable Risk? Open Arch Repair After Coronary Artery Bypass Surgery. Joseph S. Coselli. Semin Thoracic Surg 2016:36-37

Off-Pump Coronary Artery Bypass Grafting Bobby Yanagawa. Oper Tech Thorac Cardiovasc 2016:2-18

Total Arterial Revascularization Silvana Marasco. Oper Tech Thorac Cardiovasc 2016:19-29 


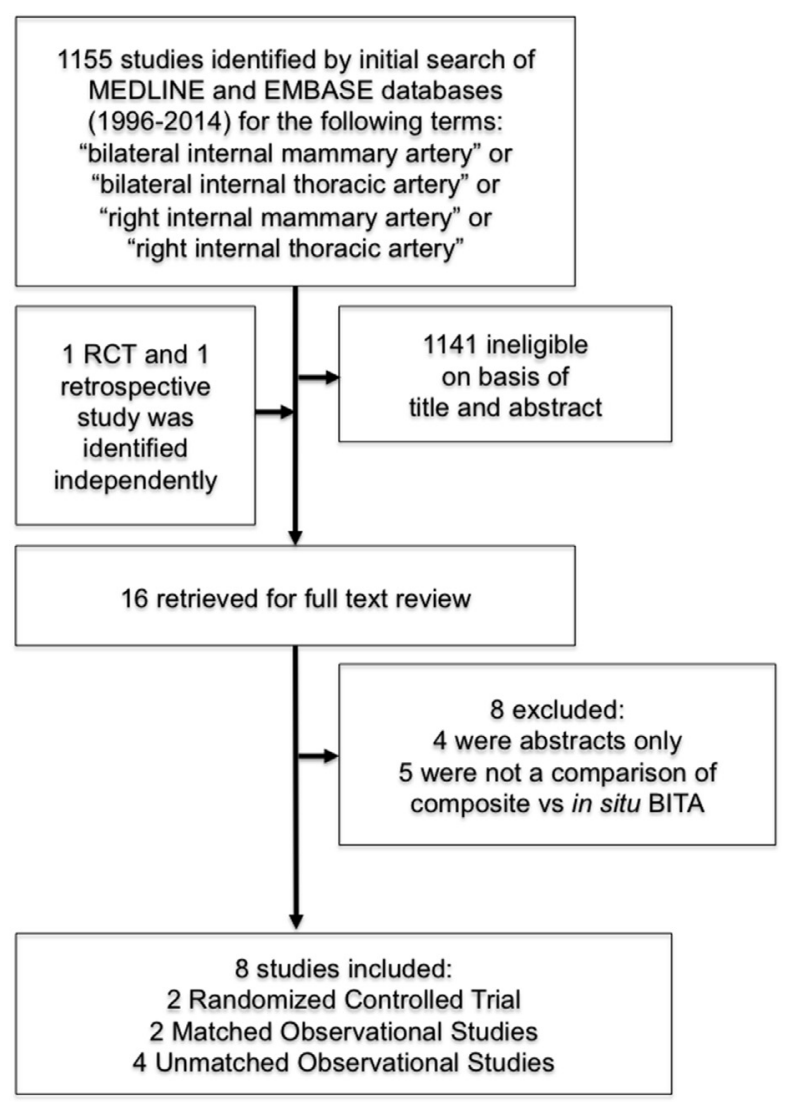

FIGURE E1. Search strategy and trial flow. Flow chart for the systematic review and meta-analysis showing the search strategy and the number of studies retained and number of studies excluded with reason for exclusion at each stage of the study selection process. RCT, Randomized controlled trial; BITA, bilateral internal thoracic artery. 


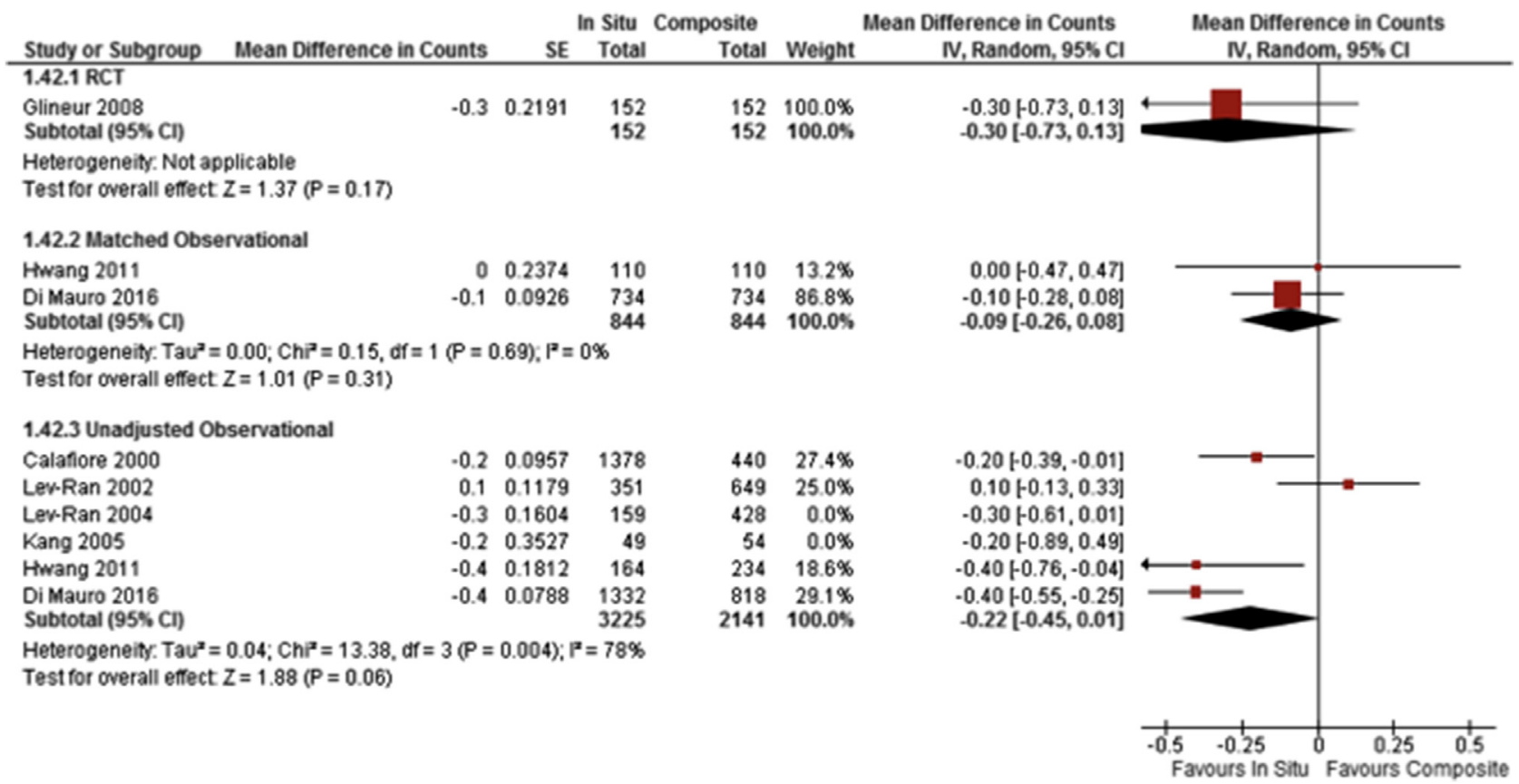

FIGURE E2. Forest plot for total distal anastomoses. Individual study and pooled mean differences in total distal anastomoses in RCTs versus matched observational studies versus unadjusted observational studies comparing patients with in situ versus composite BITA. The pooled mean differences with $95 \%$ CI were calculated by the use of random-effects models. There were no differences between the pooled result of the RCTs versus the pooled result of the matched observational studies versus the pooled result of the unadjusted observational studies (pairwise comparison interaction $P=.36-.75$ ). Only the 2002 paper by Lev-Ran and colleagues ${ }^{20}$ and not the 2004 paper by Lev-Ran and colleagues, ${ }^{21}$ and only Hwang and colleagues ${ }^{15}$ but not Kang and colleagues $^{22}$ were included in the pooled analysis to avoid duplicate counting of some patients, given likely partial overlapping patient populations in these 2 pairs of studies. The decrease in total distal anastomoses in the subgroup of unadjusted observational studies is statistically significant if either the data from the 2004 paper of Lev-Ran and colleagues ${ }^{21}$ is used instead of the 2002 paper of Lev-Ran and colleagues ${ }^{20}$ (MD, $-0.32 ; 95 \%$ CI, -0.43 to -0.22 anastomoses/patient, $P<.00001, I^{2}=0 \%$ ) or the data from both studies of Lev-Ran and colleagues are included (MD, $-0.23 ; 95 \%$ CI, -0.42 to $-0.04, P=.02, I^{2}=70 \%$ ), or the data from both pairs of overlapping studies are included (MD, $-0.23 ; 95 \%$ CI, -0.41 to $-0.06, P=.01$, $\left.I^{2}=63 \%\right)$. SE, Standard error; $C I$, confidence interval; $R C T$, randomized controlled trial. 


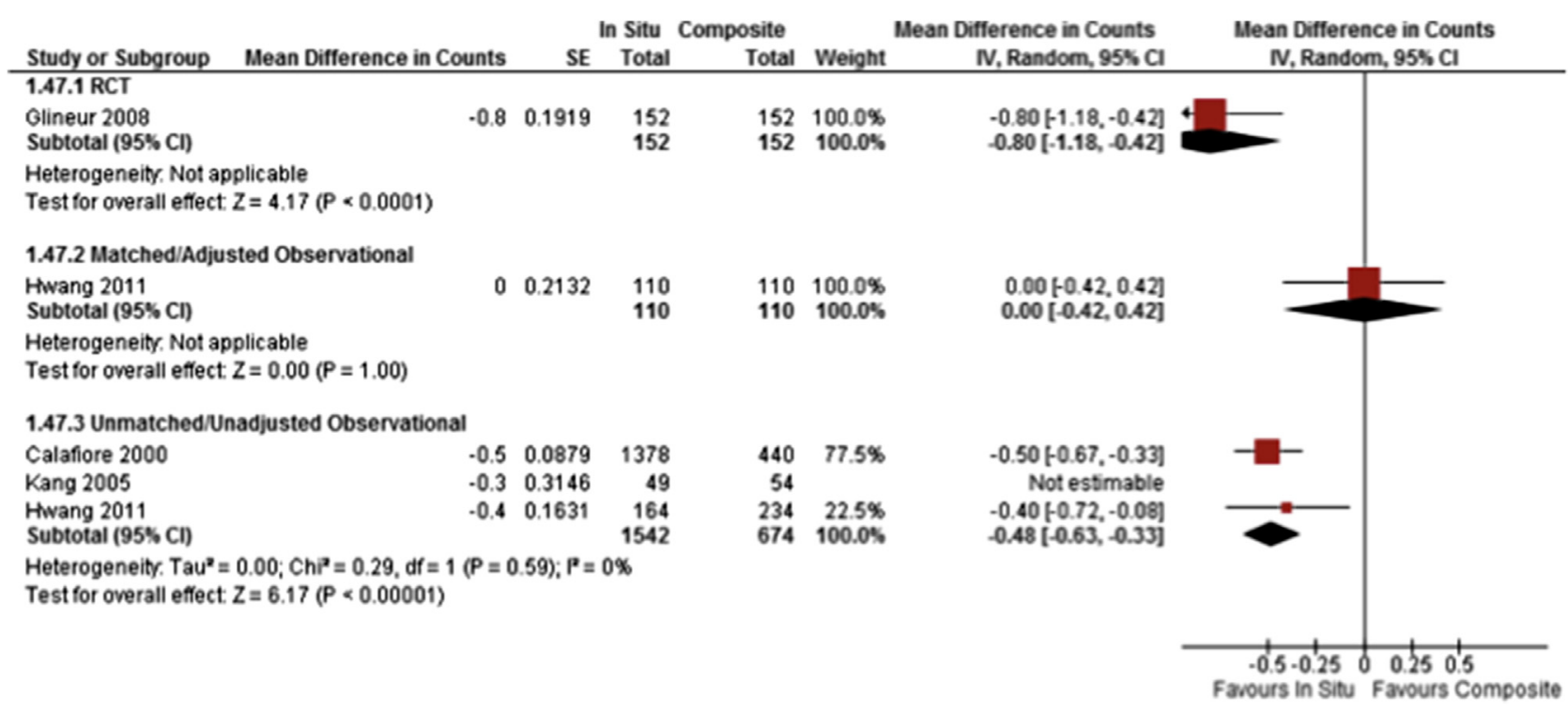

FIGURE E3. Forest plot for ITA distal anastomoses. Individual study and pooled MD for total distal anastomoses in RCTs versus matched observational studies versus unadjusted observational studies comparing patients with in situ versus composite BITA. The pooled mean differences with $95 \%$ CI were calculated by the use of random-effects models. As shown in the figure, both the RCT and unadjusted observational study subgroups demonstrated statistically significant decreases in ITA distal anastomoses for in situ versus composite BITA, although the decrease in the RCT subgroup was larger but not statistically different (interaction $P=.12$ ). Pooled results were different compared with the matched observational subgroup for both the RCT (interaction $P=.005$ ) and unadjusted observational (interaction $P=.04$ ) subgroups. Only Hwang and colleagues ${ }^{15}$ and not Kang and colleagues ${ }^{22}$ was included in the pooled analysis of the unadjusted observational subgroup to avoid duplicate counting of some patients, given likely partial overlapping patient populations in this pair of studies. If data from both of these studies are included, the pooled decrease in the number of ITA distal anastomoses in the unadjusted observational subgroup is not significantly changed (MD, $-0.47 ; 95 \%$ CI, -0.61 to -0.32 anastomoses/patient, $P<.00001$, $I^{2}=0 \%$ ). SE, Standard error; $C I$, confidence interval; $R C T$, randomized controlled trial. 


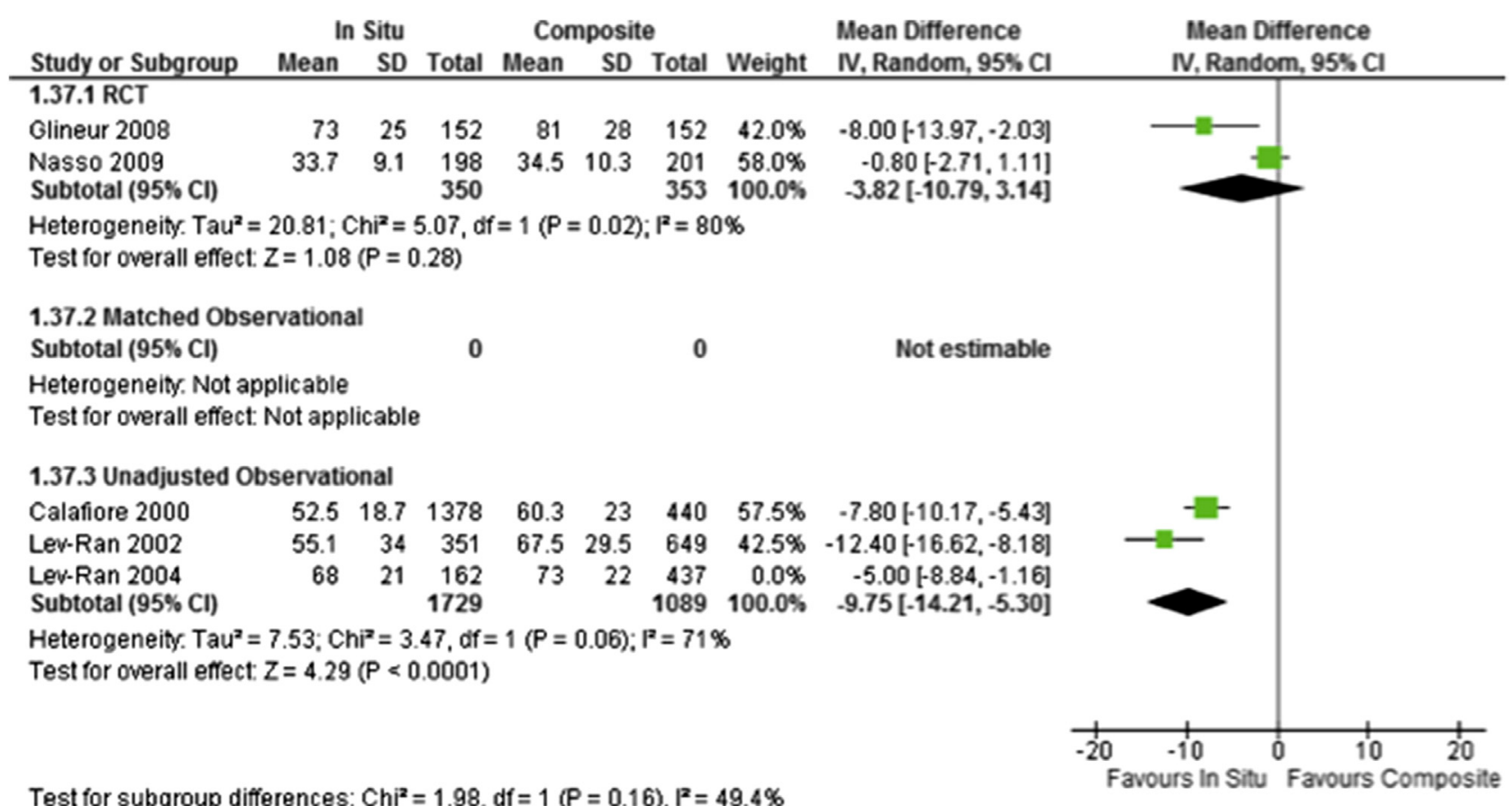

FIGURE E4. Forest plot of crossclamp time. Individual study and pooled MD for crossclamp time in RCTs versus matched observational studies versus unadjusted observational studies comparing patients with in situ versus composite BITA. The pooled mean differences with $95 \%$ CI were calculated by the use of random-effects models. For Glineur and colleagues, ${ }^{26}$ standard deviations were estimated based on reported means and $P$ values. As shown in the figure, the decreases in crossclamp time for in situ versus composite BITA between the RCT and unadjusted observational study subgroups were similar (interaction $P=.16$ ) but only the decrease in the unadjusted observational study subgroup was statistically significant $(P<.0001)$. Only the 2002 paper of Lev-Ran and colleagues ${ }^{20}$ and not the 2004 paper of Lev-Ran and colleagues ${ }^{21}$ was included in the pooled analysis of the unadjusted observational subgroup to avoid duplicate counting of some patients, given likely partial overlapping patient populations in this pair of studies. If data from both of these studies are included, the pooled decrease in the crossclamp time in the unadjusted observational subgroup is not significantly changed (MD, $-8.26 ; 95 \%$ CI, -11.84 to -4.68 minutes, $P<.00001, I^{2}=69 \%$ ). $S D$, Standard deviation; $C I$, confidence interval; $R C T$, randomized controlled trial. 


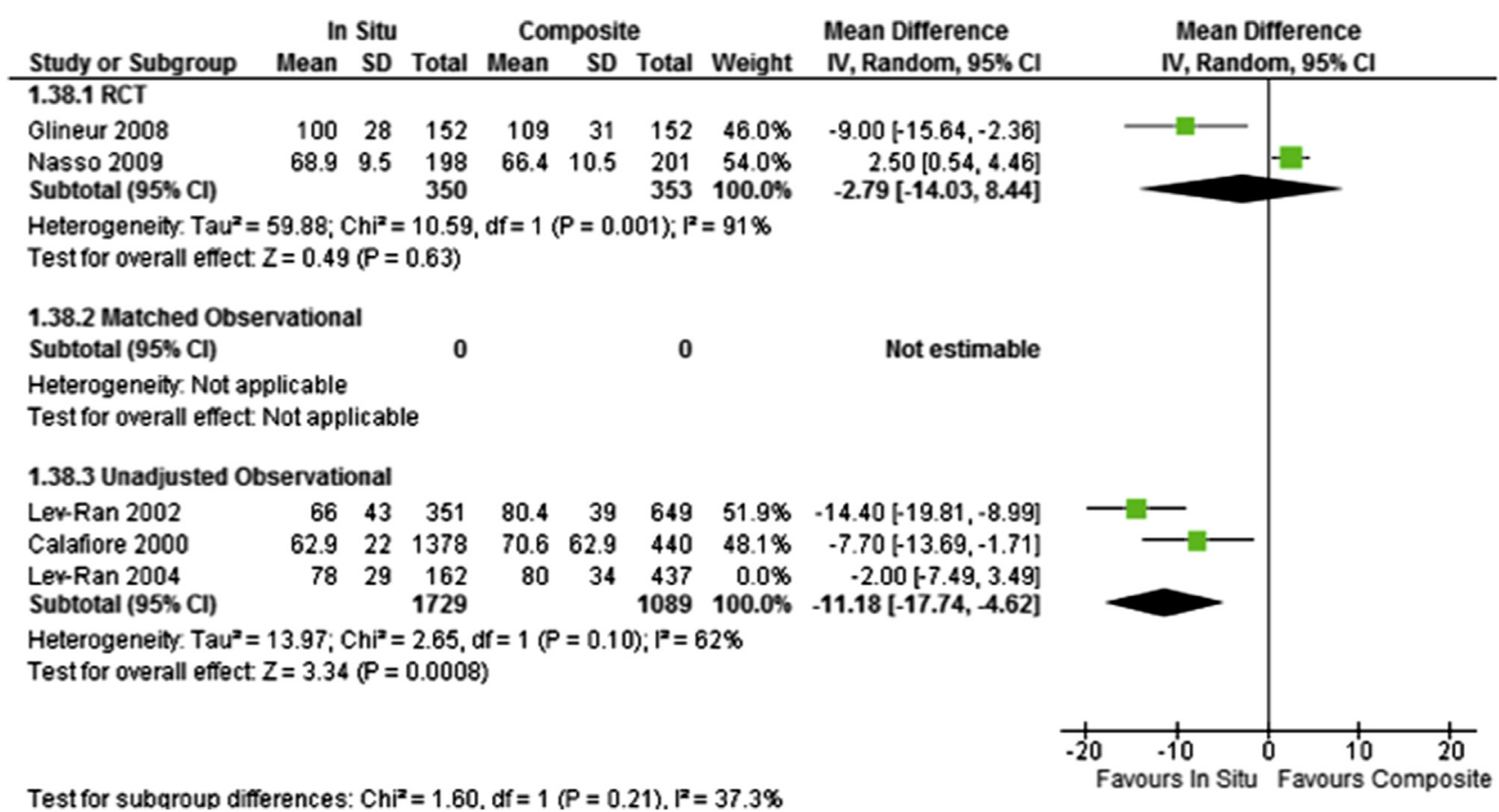

FIGURE E5. Forest plot of cardiopulmonary bypass time. Individual study and pooled MD for coronary pulmonary bypass time in RCTs versus matched observational studies versus unadjusted observational studies comparing patients with in situ versus composite BITA. The pooled mean differences with $95 \%$ CI were calculated by the use of random-effects models. For Glineur and colleagues, ${ }^{26}$ standard deviations were estimated based on reported means and $P$ values. As shown in the figure, the decreases in crossclamp time for in situ versus composite BITA between the RCT and unadjusted observational study subgroups were similar (interaction $P=.21$ ) but only decrease in the unadjusted observational study subgroup was statistically significant $(P=.0008)$. Only the 2002 paper of Lev-Ran and colleagues ${ }^{20}$ and not the 2004 paper of Lev-Ran and colleagues ${ }^{21}$ was included in the pooled analysis of the unadjusted observational subgroup to avoid duplicate counting of some patients, given likely partial overlapping patient populations in this pair of studies. If data from both of these studies are included, the pooled decrease in the crossclamp time in the unadjusted observational subgroup is not significantly changed (MD, $-8.05 ; 95 \% \mathrm{CI},-15.30$ to -0.80 minutes, $P=.03, I^{2}=80 \%$ ). $S D$, Standard deviation; $C I$, confidence interval; $R C T$, randomized controlled trial. 


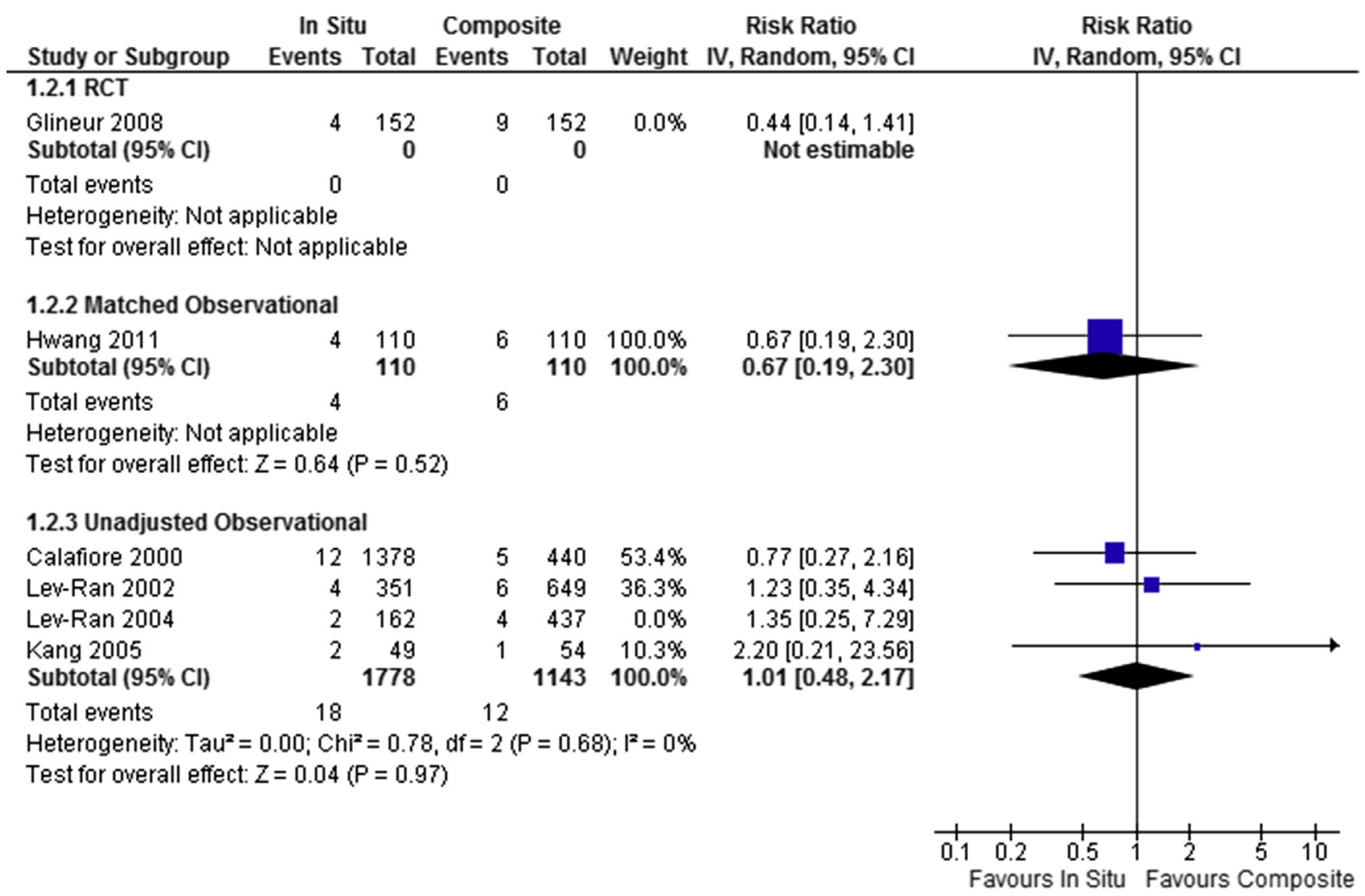

FIGURE E6. Forest plot for 30-day mortality. Individual study and pooled RRs for 30-day mortality in RCTs versus matched observational studies versus unadjusted observational studies comparing patients with in situ versus composite BITA. The pooled RRs with $95 \%$ CI were calculated by the use of random-effects models. There were no differences between the pooled result of the RCTs versus the pooled result of the matched observational studies versus the pooled result of the unadjusted observational studies (pairwise comparison interaction $P=.27-.86$ ). Only the 2002 paper of Lev-Ran and colleagues $^{20}$ and not the 2004 paper of Lev-Ran and colleagues ${ }^{21}$ was included in the pooled analysis to avoid duplicate counting of some patients, given likely partial overlapping patient populations in these 2 studies. Including data from both these studies results in minimal changes to the pooled result for the unadjusted observational studies (RR, 0.78 ; 95\% CI, $0.49-1.24, P=.29, I^{2}=0 \%$ ). Mean overall incidence rate for 30-day mortality was $2.2 \%$. $C I$, Confidence interval; RCT, randomized controlled trial. 


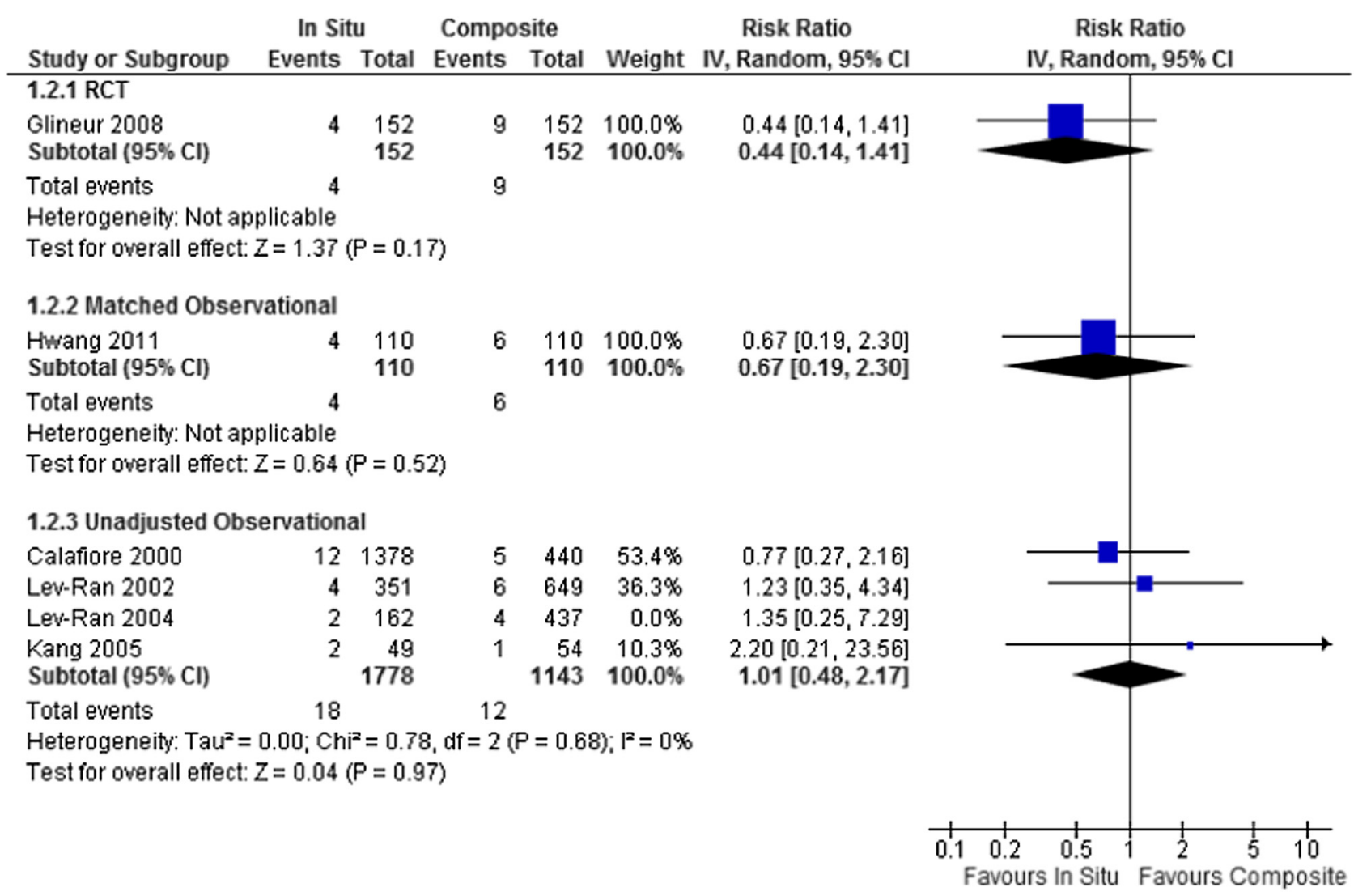

FIGURE E7. Forest plot for perioperative MI. Individual study and pooled RRs for perioperative MI in RCTs versus matched observational studies versus unadjusted observational studies comparing patients with in situ versus composite BITA. The pooled RRs with $95 \%$ CI were calculated by the use of random-effects models. There were no differences between the pooled result of the RCTs versus the pooled result of the matched observational studies versus the pooled result of the unadjusted observational studies (pairwise comparison interaction $P=.24-.64$ ). Only the 2002 paper of Lev-Ran and colleagues ${ }^{20}$ and not the 2004 paper of Lev-Ran and colleagues ${ }^{21}$ was included in the pooled analysis to avoid duplicate counting of some patients, given likely partial overlapping patient populations in these studies. Including data from both these studies results in no significant changes to the pooled result for the unadjusted observational studies (RR, $1.06 ; 95 \% \mathrm{CI}, 0.53-2.13, P=.86, I^{2}=0 \%$ ). Mean overall incidence rate for perioperative MI was $1.5 \%$. $C I$, Confidence interval; $R C T$, randomized controlled trial. 


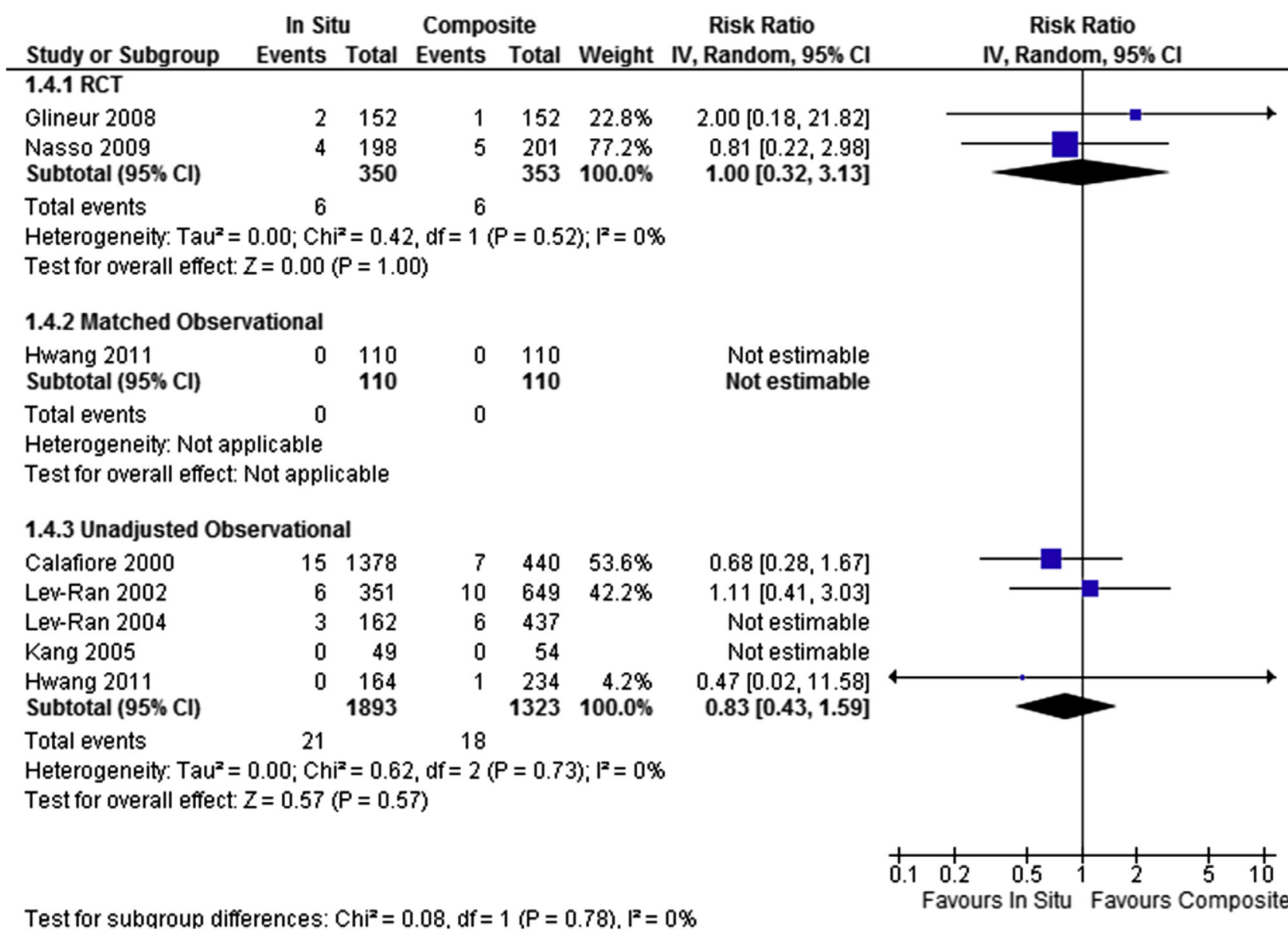

FIGURE E8. Forest plot for perioperative stroke. Individual study and pooled RRs for perioperative stroke in RCTs versus matched observational studies versus unadjusted observational studies comparing patients with in situ versus composite BITA. The pooled RRs with $95 \%$ CI were calculated by the use of random-effects models. There were no differences between the pooled result of the RCTs versus the pooled result of the unadjusted observational studies (interaction $P=.78$ ). Only the 2002 paper of Lev-Ran and colleagues ${ }^{20}$ and not the 2004 paper of Lev-Ran and colleagues, ${ }^{21}$ and only Hwang and colleagues ${ }^{15}$ and not Kang and colleagues ${ }^{22}$ were included in the pooled analysis to avoid duplicate counting of some patients, given likely partial overlapping patient populations in these 2 pairs of studies. Including data from both pairs of these studies results in no significant changes to the pooled result of the unadjusted observational studies: RR, $0.90 ; 95 \% \mathrm{CI}, 0.50-1.63, P=.74, I^{2}=0 \%$. Mean overall incidence rate for perioperative stroke was $1.3 \%$. $C I$, Confidence interval; $R C T$, randomized controlled trial. 


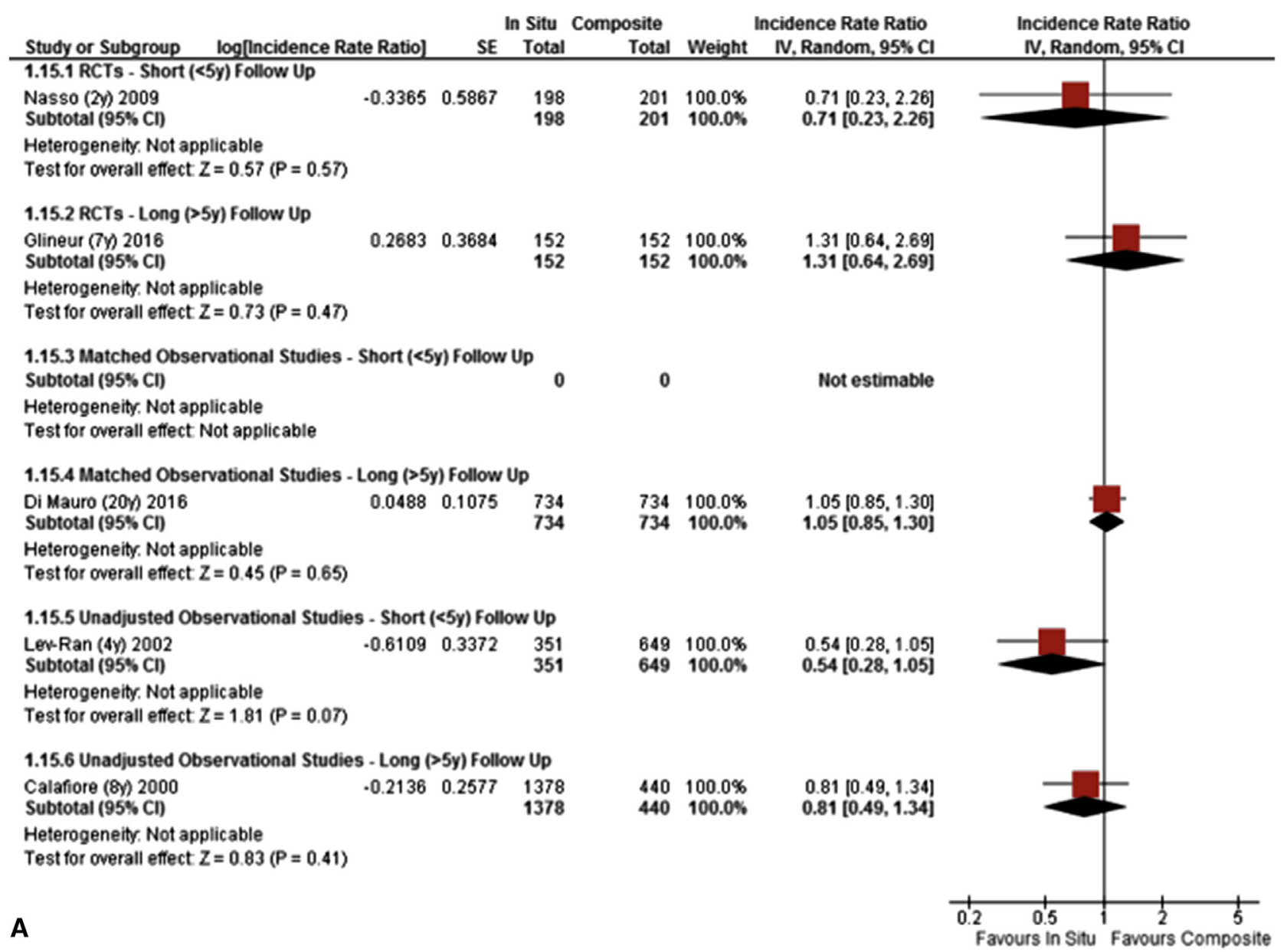

FIGURE E9. Forest plot for (A) all-cause mortality, (B) MACE, and (C) repeat revascularization by duration of follow-up. Individual study and pooled incidence rate ratios comparing studies with shorter versus longer term follow-up using a threshold of 5 years separately for RCTs, matched observational studies and unadjusted observational studies comparing patients with in situ versus composite BITA. The time point that Kaplan-Meier survival curve outcome event estimates, or mean follow-up when absolute outcome events were reported in each study are shown in brackets after author name. The pooled incident rate ratios with $95 \%$ CIs were calculated using random-effects models. The lower mortality (A) incident rate ratio in the shorter follow-up study was not statistically different than the incident rate ratio in the longer follow-up study for both the RCTs (interaction $P=.38$ ) and unadjusted observational studies (interaction $P=.35$ ). The lower MACE (B) incident rate ratio in the shorter follow-up study was not statistically different than the incident rate ratio in the longer follow-up study for the RCTs (interaction $P=.40$ ). Comparing the lower revascularization $(\mathrm{C})$ incident rate ratio of in situ versus composite BITA in the shorter follow-up study to the incident rate ratio in the longer follow-up studies yields an interaction $P=.08$ for the unadjusted observational studies. $S E$, Standard error; $C I$, confidence interval; $R C T$, randomized controlled trial. 


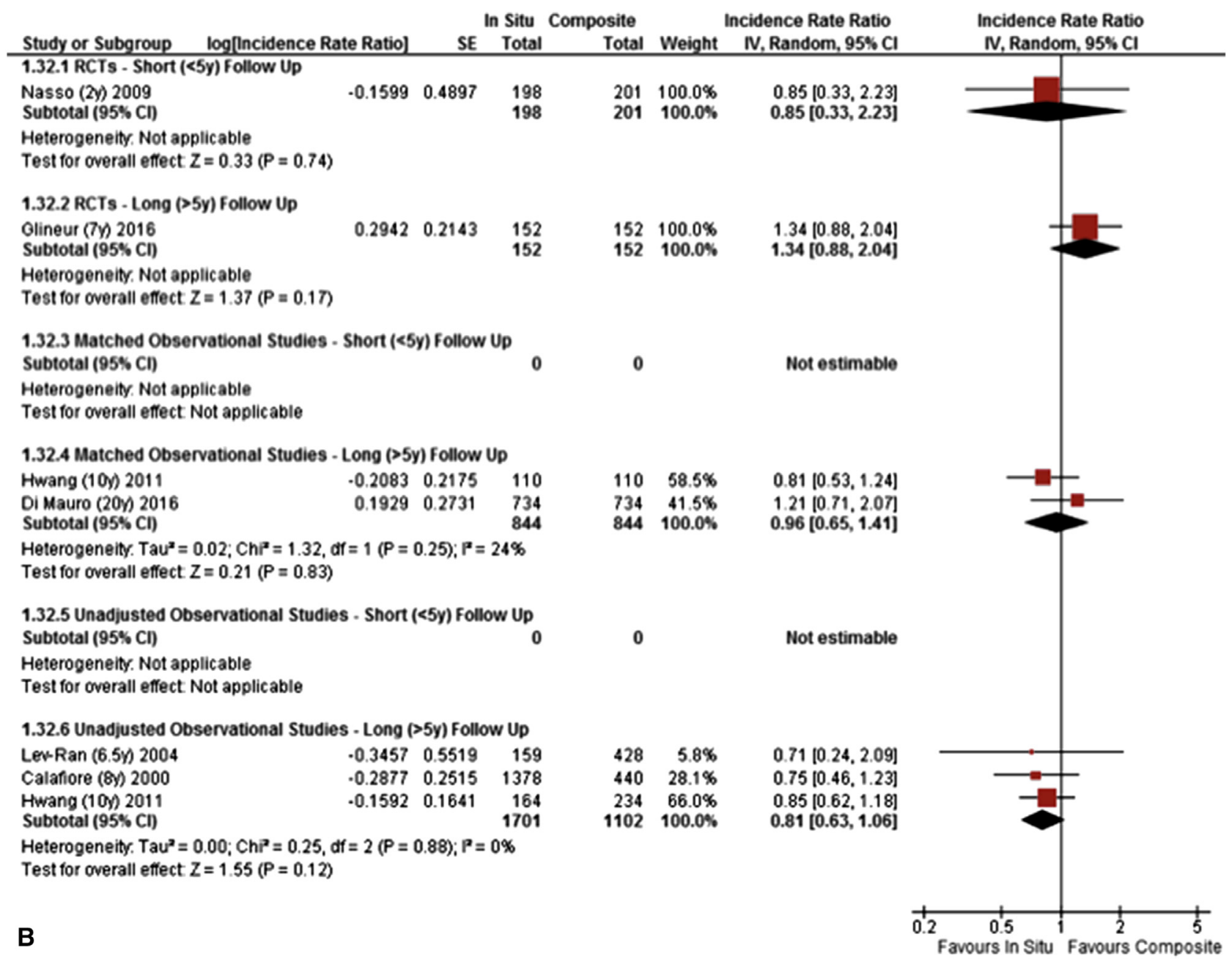

FIGURE E9. (Continued). 


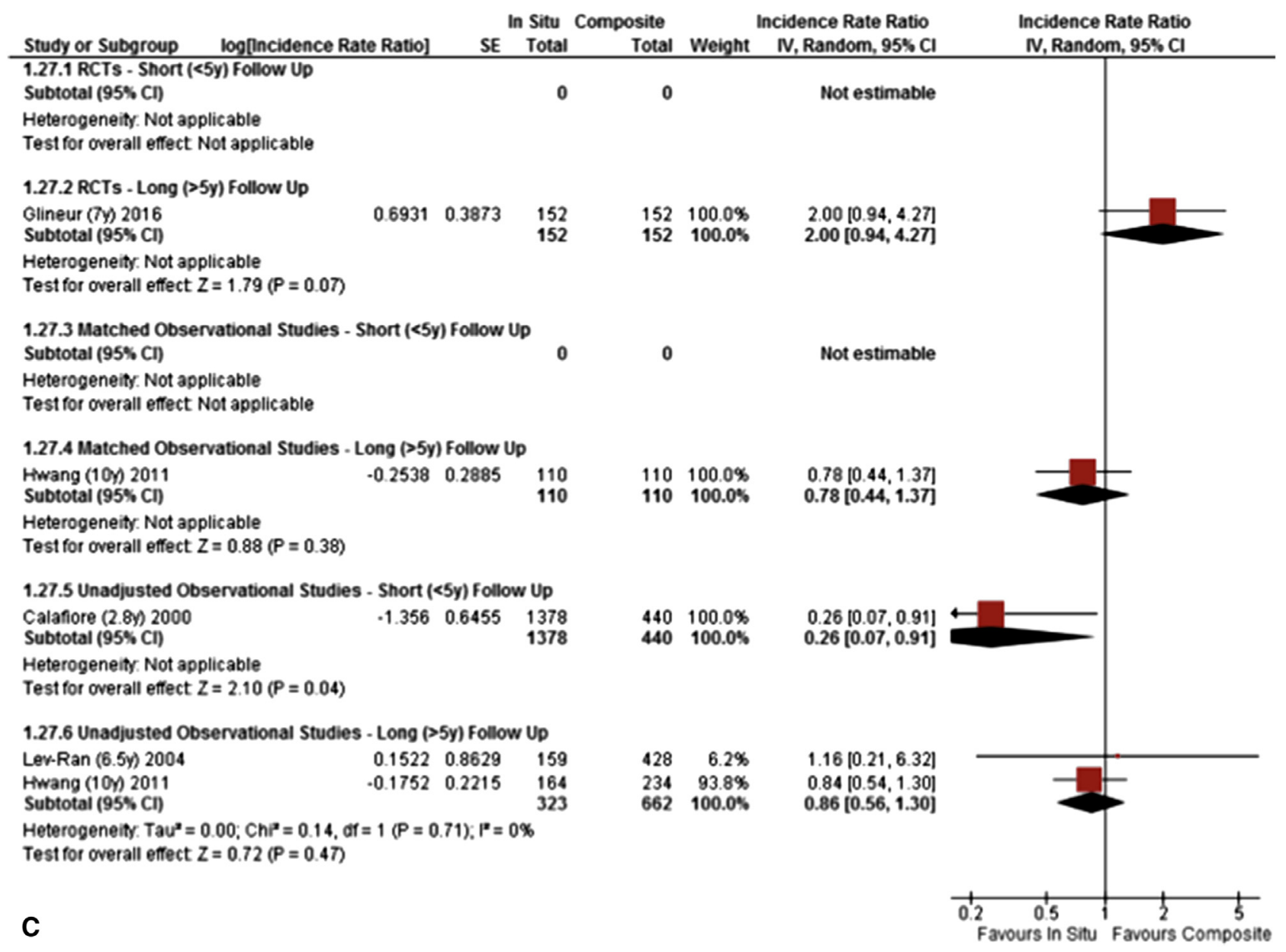

FIGURE E9. (Continued). 
TABLE E1. Incidence rate ratio calculations used for generic inverse variance meta-analysis

\begin{tabular}{|c|c|c|c|c|}
\hline \multicolumn{3}{|c|}{ Numbers of patients and FU durations } & \multicolumn{2}{|c|}{ MACE } \\
\hline In situ & Composite & All & In situ & Composite \\
\hline
\end{tabular}

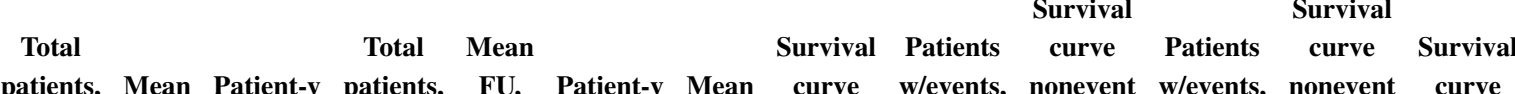

\begin{tabular}{|c|c|c|c|c|c|c|c|c|c|c|c|c|c|c|c|c|}
\hline Study & $\mathbf{N}$ & FU, $\mathbf{y}$ & FU & $\mathbf{N}$ & $\mathbf{y}$ & FU & FU, $\mathbf{y}$ & FU, $\mathbf{y}$ & $\mathbf{n}$ & rate & $\mathbf{n}$ & rate & $P$ value & IRR* & Ln(IRR) & SE[Ln(IRR) \\
\hline \multicolumn{17}{|c|}{ Tandomized controlled trials } \\
\hline Nasso et al, $2009^{27}$ & 198 & & & 201 & & & 2 & 3 & & $90.5 \%$ & & $88.8 \%$ & .744 & 0.852 & -0.160 & 0.490 \\
\hline Glineur et al, $2016^{25} \ddagger$ & 152 & 7 & 1064 & 152 & 7 & 1064 & 7 & & 51 & & 38 & & & 1.342 & 0.294 & 0.214 \\
\hline \multicolumn{17}{|c|}{ Matched observational studies } \\
\hline Hwang et al, 2011 $1^{15}$ & 110 & & & 110 & & & 8.67 & 10 & & $82.3 \%$ & & $78.2 \%$ & .338 & 0.812 & -0.208 & 0.217 \\
\hline Di Mauro et al, $2016^{16}$ & 734 & & & 734 & & & 16.67 & 20 & 299 & $43 \%$ & 246 & $53 \%$ & .48 & 1.213 & 0.193 & 0.273 \\
\hline \multicolumn{17}{|c|}{ Inmatched observational studies } \\
\hline Calafiore et al, $2000^{28}$ & 1378 & 2.96 & 4077 & 440 & 1.59 & 700 & 2.8 & 8 & 64 & $95.2 \%$ & 21 & $93.6 \%$ & $\mathrm{n} / \mathrm{a}$ & 0.750 & -0.288 & 0.251 \\
\hline Lev-Ran et al, $2002^{20}$ & 351 & & & 649 & & & 2.67 & 4 & & & & & & & & \\
\hline Lev-Ran et al, $2004^{21}$ & 159 & & & 428 & & & 3.5 & 6.5 & & $86.2 \%$ & & $80.5 \%$ & .531 & 0.708 & -0.346 & 0.552 \\
\hline Hwang et al, $2011^{15}$ & 164 & & & 234 & & & 8.67 & 10 & & $83.2 \%$ & & $80.3 \%$ & .332 & 0.853 & -0.159 & 0.164 \\
\hline
\end{tabular}

$M A C E$, Major adverse cardiac event; $F U$, follow-up; $S E$, standard error; $I R R$, incident rate ratios; $n / a$, not available. $*$ IRR: If survival curve nonevent rate proportions are available, then IRR $=(1-$ in situ nonevent rate $) /(1-$ composite nonevent rate). If the actual number of patients with events and group specific patient-years of follow-up are available, then IRR $=$ [in situ event patients/in situ patient-years of follow-up]/[composite event patients/composite patient-years of follow-up]. $\nmid \operatorname{SE}[\operatorname{Ln}(\operatorname{IRR})]$ : If the survival curve $P$ value was available, then it was calculated with the NORMSINV function in Microsoft Excel (Redmond, Wash), SE[Ln(IRR)] $=\operatorname{Ln}(\operatorname{IRR}) / \mathrm{NORMSINV}(P$ value/2). If only actual events were available, then $\operatorname{SE}[\operatorname{Ln}(\operatorname{IRR})]=(1 / \text { in situ event patients }+1 / \text { Composite event patients })^{1 / 2}$. 
TABLE E2. Incidence rate ratio calculations used for generic inverse variance meta-analysis

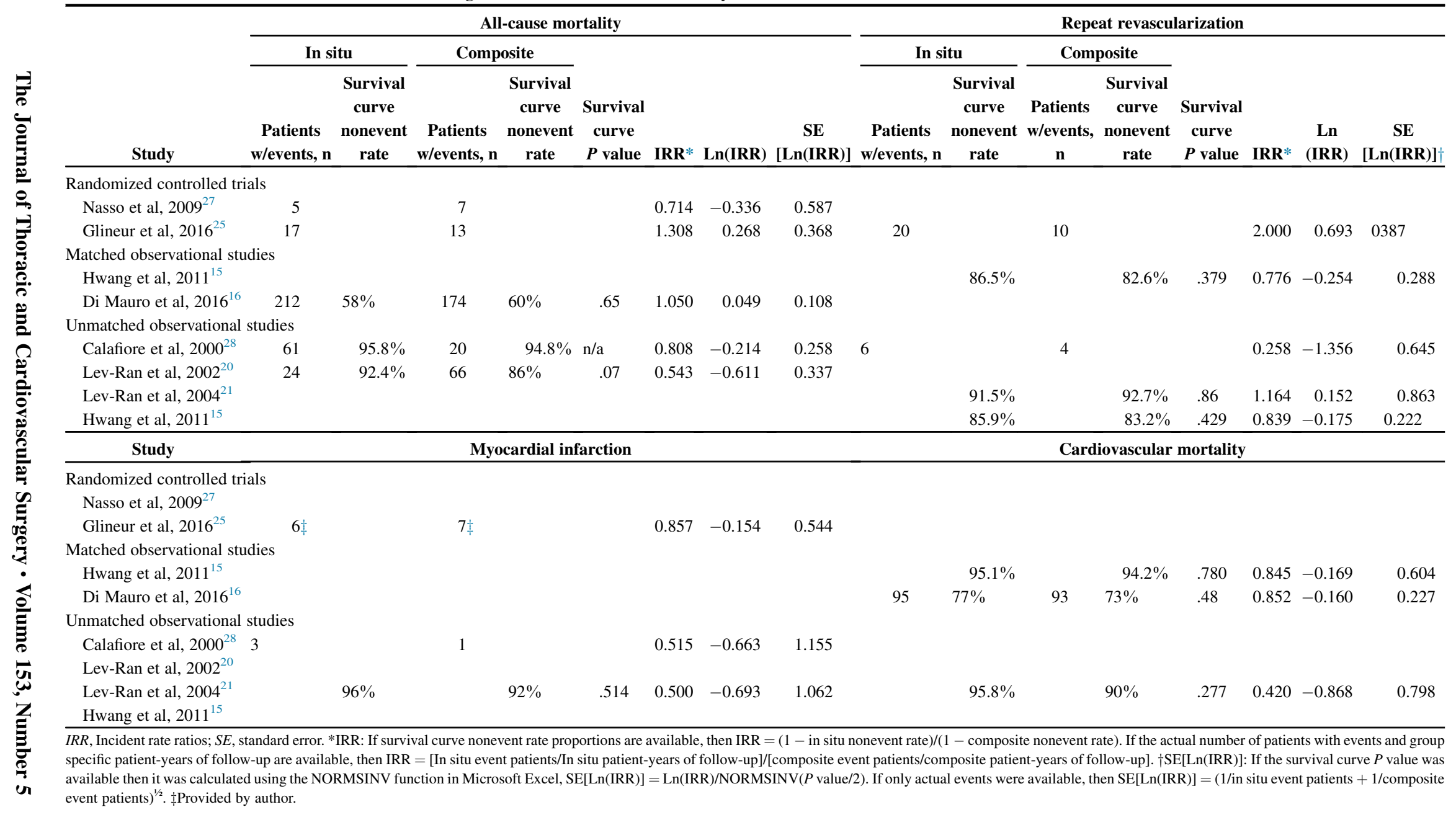


TABLE E3. PRISMA checklist

\begin{tabular}{|c|c|c|c|}
\hline Section/topic & \# & Checklist item & Reported on page \# \\
\hline \multicolumn{4}{|l|}{ TITLE } \\
\hline Title & 1 & Identify the report as a systematic review, meta-analysis, or both. & 1 \\
\hline \multicolumn{4}{|l|}{ ABSTRACT } \\
\hline Structured summary & 2 & $\begin{array}{l}\text { Provide a structured summary including, as applicable: background; objectives; } \\
\text { data sources; study eligibility criteria, participants, and interventions; study } \\
\text { appraisal and synthesis methods; results; limitations; conclusions and } \\
\text { implications of key findings; systematic review registration number. }\end{array}$ & 1 \\
\hline \multicolumn{4}{|l|}{ INTRODUCTION } \\
\hline Rationale & 3 & Describe the rationale for the review in the context of what is already known. & $1-2$ \\
\hline Objectives & 4 & Provide an explicit statement of questions being addressed with reference to PICOS. & 2 \\
\hline \multicolumn{4}{|l|}{ METHODS } \\
\hline Protocol and registration & 5 & $\begin{array}{l}\text { Indicate if a review protocol exists, if and where it can be accessed (eg, Web } \\
\text { address), and, if available, provide registration information including } \\
\text { registration number. }\end{array}$ & 2 \\
\hline Eligibility criteria & 6 & $\begin{array}{l}\text { Specify study characteristics (eg, PICOS, length of follow-up) and report } \\
\text { characteristics (eg, years considered, language, publication status) used as } \\
\text { criteria for eligibility, giving rationale. }\end{array}$ & 2 \\
\hline Information sources & 7 & $\begin{array}{l}\text { Describe all information sources (eg, databases with dates of coverage, contact with } \\
\text { study authors to identify additional studies) in the search and date last } \\
\text { searched. }\end{array}$ & 2 \\
\hline Search & 8 & $\begin{array}{l}\text { Present full electronic search strategy for at least one database, including any limits } \\
\text { used, such that it could be repeated. }\end{array}$ & Figure E1 \\
\hline Study selection & 9 & $\begin{array}{l}\text { State the process for selecting studies (ie, screening, eligibility, included in } \\
\text { systematic review, and, if applicable, included in the meta-analysis). }\end{array}$ & 2 \\
\hline Data collection process & 10 & $\begin{array}{l}\text { Describe method of data extraction from reports (eg, piloted forms, independently, } \\
\text { in duplicate) and any processes for obtaining and confirming data from } \\
\text { investigators. }\end{array}$ & 2 \\
\hline Data items & 11 & $\begin{array}{l}\text { List and define all variables for which data were sought (eg, PICOS, funding } \\
\text { sources) and any assumptions and simplifications made. }\end{array}$ & 2 \\
\hline Risk of bias in individual studies & 12 & $\begin{array}{l}\text { Describe methods used for assessing risk of bias of individual studies (including } \\
\text { specification of whether this was done at the study or outcome level), and how } \\
\text { this information is to be used in any data synthesis. }\end{array}$ & 2 \\
\hline Summary measures & 13 & State the principal summary measures (eg, risk ratio, difference in means). & $2-4$ \\
\hline Synthesis of results & 14 & $\begin{array}{l}\text { Describe the methods of handling data and combining results of studies, if done, } \\
\text { including measures of consistency }\left(\mathrm{eg}, \mathrm{I}^{2}\right) \text { for each meta-analysis. }\end{array}$ & $2-4$ \\
\hline
\end{tabular}

PICOS, Participants, interventions, comparisons, outcomes, and study design. 
TABLE E4. PRISMA checklist, continued

\begin{tabular}{|c|c|c|c|}
\hline Section/topic & $\#$ & Checklist item & Reported on page \# \\
\hline Risk of bias across studies & 15 & $\begin{array}{l}\text { Specify any assessment of risk of bias that may affect the cumulative evidence (eg, } \\
\text { publication bias, selective reporting within studies). }\end{array}$ & $2-3$ \\
\hline Additional analyses & 16 & $\begin{array}{l}\text { Describe methods of additional analyses (eg, sensitivity or subgroup analyses, meta- } \\
\text { regression), if done, indicating which were pre-specified. }\end{array}$ & $2-3$ \\
\hline \multicolumn{4}{|l|}{ RESULTS } \\
\hline Study selection & 17 & $\begin{array}{l}\text { Give numbers of studies screened, assessed for eligibility, and included in the review, with } \\
\text { reasons for exclusions at each stage, ideally with a flow diagram. }\end{array}$ & 3 and Figure E1 \\
\hline Study characteristics & 18 & $\begin{array}{l}\text { For each study, present characteristics for which data were extracted (eg, study size, PICOS, } \\
\text { follow-up period) and provide the citations. }\end{array}$ & 3 Tables 1 and 2 \\
\hline Risk of bias within studies & 19 & $\begin{array}{l}\text { Present data on risk of bias of each study and, if available, any outcome level assessment } \\
\text { (see item 12). }\end{array}$ & 3, Tables 3 and 4 \\
\hline Results of individual studies & 20 & $\begin{array}{l}\text { For all outcomes considered (benefits or harms), present, for each study: (a) simple } \\
\text { summary data for each intervention group (b) effect estimates and confidence intervals, } \\
\text { ideally with a forest plot. }\end{array}$ & $\begin{array}{r}\text { 2-4 and Figures 1-5, } \\
\text { Figures E2-E10 }\end{array}$ \\
\hline Synthesis of results & 21 & $\begin{array}{l}\text { Present results of each meta-analysis done, including confidence intervals and measures of } \\
\text { consistency. }\end{array}$ & $\begin{array}{r}\text { 2-4 and Figures 1-5, } \\
\text { Figures E2-E10 }\end{array}$ \\
\hline Risk of bias across studies & 22 & Present results of any assessment of risk of bias across studies (see Item 15). & 2 \\
\hline Additional analysis & 23 & $\begin{array}{l}\text { Give results of additional analyses, if done (eg, sensitivity or subgroup analyses, meta- } \\
\text { regression [see Item 16]). }\end{array}$ & 2-4, Figures $10, A-C$ \\
\hline \multicolumn{4}{|l|}{ DISCUSSION } \\
\hline Summary of evidence & 24 & $\begin{array}{l}\text { Summarize the main findings including the strength of evidence for each main outcome; } \\
\text { consider their relevance to key groups (eg, healthcare providers, users, and policy } \\
\text { makers). }\end{array}$ & 4 \\
\hline Limitations & 25 & $\begin{array}{l}\text { Discuss limitations at study and outcome level (eg, risk of bias), and at review-level (eg, } \\
\text { incomplete retrieval of identified research, reporting bias). }\end{array}$ & 8 \\
\hline Conclusions & 26 & $\begin{array}{l}\text { Provide a general interpretation of the results in the context of other evidence, and } \\
\text { implications for future research. }\end{array}$ & 8 \\
\hline \multicolumn{4}{|l|}{ FUNDING } \\
\hline Funding & 27 & $\begin{array}{l}\text { Describe sources of funding for the systematic review and other support (eg, supply of } \\
\text { data); role of funders for the systematic review. }\end{array}$ & 1 \\
\hline
\end{tabular}

PICOS, Participants, interventions, comparisons, outcomes, and study design. Adapted from Moher D, Liberati A, Tetzlaff J, Altman DG, The PRISMA Group. Preferred reporting items for systematic reviews and meta-analyses: the PRISMA statement. PLoS Med. 2009;6:e1000097. For more information, visit: www.prisma-statement.org.

TABLE E5. Quality assessment of included randomized controlled trials

\begin{tabular}{|c|c|c|c|c|c|c|c|c|}
\hline Author $(y)$ country & $\begin{array}{c}\text { No. } \\
\text { centers }\end{array}$ & $\begin{array}{c}\text { No. } \\
\text { patients }\end{array}$ & Blinding & $\begin{array}{c}\text { Adequate } \\
\text { sequence } \\
\text { generation }\end{array}$ & $\begin{array}{l}\text { Concealed } \\
\text { allocation }\end{array}$ & $\begin{array}{c}\text { Intention-to-treat } \\
\text { analysis }\end{array}$ & $\begin{array}{c}\text { Not stopped } \\
\text { early for benefit }\end{array}$ & $\begin{array}{c}\text { Postrandomization } \\
\text { withdrawal }\end{array}$ \\
\hline $\begin{array}{l}{\text { Glineur et } \mathrm{al}^{27}}^{2016)} \\
\text { Belgium }\end{array}$ & 1 & 304 & $\mathrm{~N}$ & NR & NR & Y & $\mathrm{Y}$ & $\mathrm{N}$ \\
\hline Nasso et al ${ }^{29}$ (2009) Italy & 1 & 406 & $\mathrm{~N}$ & $\mathrm{Y}$ (computer) & NR & Y & Y & $\begin{array}{c}\mathrm{Y} \\
(7 / 406[2 \%])\end{array}$ \\
\hline
\end{tabular}

$N$, No; $N R$, not reported; $Y$, yes. 
TABLE E6. Quality assessment of included retrospective studies

\begin{tabular}{|c|c|c|c|c|c|}
\hline Author $(y)$ country & $\begin{array}{l}\text { No. } \\
\text { centers }\end{array}$ & $\begin{array}{c}\text { No. } \\
\text { patients }\end{array}$ & $\begin{array}{l}\text { Prospective/ } \\
\text { retrospective }\end{array}$ & Concurrent control & Comparable baseline \\
\hline Calafiore et $\mathrm{al}^{28}$ (2000) Italy & 1 & 1818 & Retrospective & $\mathrm{Y}$ (surgeon discretion) & $\begin{array}{l}\mathrm{N} \text { (more patients with diabetes or with need for an } \\
\text { urgent or second procedure, and lower ejection } \\
\text { fraction in composite group) }\end{array}$ \\
\hline Lev-Ran et $\mathrm{al}^{20}$ (2002) Israel & 1 & 1000 & Retrospective & $\mathrm{Y}$ (surgeon discretion) & $\begin{array}{l}\mathrm{N} \text { (more women, more patients with diabetes and } \\
\text { preoperative myocardial infarction in composite } \\
\text { group) }\end{array}$ \\
\hline Lev-Ran et $\mathrm{al}^{21}$ (2004) Israel & 1 & 515 (diabetic) & Retrospective & Y (surgeon discretion) & $\mathrm{Y}$ \\
\hline Kang et $\mathrm{al}^{22}$ (2005) Korea & 1 & 103 & Prospective & $\mathrm{Y}$ (surgeon discretion) & $\mathrm{Y}$ \\
\hline Hwang et $\mathrm{al}^{15}$ (2011) Korea & 1 & 398 & Retrospective & $\mathrm{Y}$ (surgeon discretion) & $\begin{array}{l}\text { Y (after propensity matching)/older with more } \\
\text { frequent left main and 3-vessel coronary disease in } \\
\text { composite group before propensity matching }\end{array}$ \\
\hline Di Mauro et al $^{16}$ (2016) Egypt & 1 & 2150 & Retrospective & $\mathrm{Y}$ (surgeon discretion) & $\begin{array}{l}\text { Y (after propensity matching)/more chronic renal } \\
\text { failure but fewer previous myocardial infarctions } \\
\text { and less unstable angina/urgent cases and less left } \\
\text { main disease in composite group before propensity } \\
\text { matching }\end{array}$ \\
\hline
\end{tabular}

$Y$, Yes; $N$, no. 